\title{
Beiträge zur Faunistik und Biologie der Orthopteren Algeriens und Tunesiens.
}

Von

\author{
Prof. Dr. J. Vosseler, Stuttgart.
}

Hierzu Tafel 17, 18 und 8 Abbildungen im Text.

\section{Einleitung.}

Nach der neuesten Zusammenstellung Finot's beträgt die Zahl der aus Algerien und Tunesien nunmehr bekannten Orthopteren, einschliesslich der Dermaptera, 91 Genera mit 207 Arten. $^{1}$ ) Auf den ersten Blick könnten diese scheinbar grossen Zahlen auf eine relativ gründliche faunistische Durchforschung des Landes schliessen lassen. Erst nach einem Vergleich mit der Summe der mitteleuropäischen Orthopteren ${ }^{2}$ ) und nach Berücksichtigung der Thatsache, dass die Ordnung nach Norden schnell abnimmt, während andrerseits die physikalischen Verhältnisse des afrikanischen Nordrandes die Entstehung localer Formen begünstigen und zahlreiche Glieder andrer Faunen bis dorthin vordringen, kann man sich über die Unvollständigkeit der veröffentlichten faunistischen Zusammenstellungen ein Urtheil bilden. Ist auch anzunehmen, dass der grössere Theil der nordafrikanischen Arten bekannt ist, so beweisen doch selbst ganz

1) Finot, A., Faune de l'Algérie et de la Tunisie, Insectes Orthopteres, 4 Tfln., in: Ann. Soc. entomol. France, V. 64, 1895, p. 57-120 u. $401-552 ;$ V. 65,1896, p. $513-629$.

2) Nach R. TüMPEL, Die Geradflügler Mitteleuropas, Eisenach 1901, 67 Gattungen mit 164 Arten. 
gelegentliche Aufsammlungen, dass noch immer viele Arten und Varietäten zu entdecken sind.

Durch die Erfolge früherer Besuche in Oran angeregt, führte ich im Jahre 1897 und 1901 zwei weitere Reisen dorthin aus, deren Ziel das Departement Algier und die Regentschaft Tunesien bildeten. Die vorliegende Arbeit ist das Ergebniss derselben auf orthopterologischem Gebiet.

Neben systematisch-faunistischen Untersuchungen wurde, besser vorbereitet als früher und mit durch Uebung geschärftem Blick, die Vervollständigung der einmal als lückenhaft erkannten Abschnitte über die Mittel der Verbreitung und Vertheidigung und über die Anpassungserscheinungen besonders ins Auge gefasst und namentlich auch auf den Zusammenhang in der Ursächlichkeit der beobachteten Erscheinungen geachtet.

So reihte sich, eines das andere erzeugend, Capitel an Capitel, deren jedes einen Gegenstand für sich behandelt, jedes aber wieder in die Materie der andern eingreift.

Für biologische Studien eignet sich der Charakter des Landes mit seinen klimatischen Contrasten aufs Vortrefflichste. Nirgends in ganz Mitteleuropa lassen sich die Beziehungen der physikalischen Verhältnisse eines Gebietes zur Organismenwelt klarer als dort überblicken und verfolgen, und diese beinahe wie in einem übersichtlichen Schema gegebenen Umstände lassen sich zur Lösung unter andern Verhältnissen nicht aufzuklärender Fragen ausnützen.

Für das Verständniss des innigen Zusammenhanges zwischen Organismen und Aussenwelt muss billiger Weise eine ganz allgemeine Beschreibung der Bühne, auf der sich die im Folgenden geschilderten Erscheinungen abspielen, vorangehen.

\section{Uebersicht iiber die physikalischen Verhältnisse der untersuchten Gegenden.}

Nachdem ich mich früher der Fauna Orans gewidmet, suchte ich 1897 im Departement Algier, 1901 in Tunesien die begonnenen Untersuchungen fortzusetzen und zu erweitern. Die erste Reise wurde, um einen möglichst vollkommenen Ueberblick über die den geographisch unterschiedenen Gebieten eigenen Formen zu erlangen, von Algier bis Laghouat, von dort über Djelfa, Bou-Saâda, Aumale, Bouira und zurück nach Algier ausgeführt. Auf diese Weise wurde das Tell (Algier, Blidah), der kleine Atlas (Medeah, Berrouaghia, 
Boghar), das Hochplateau der Steppen und Dünen (Bou-Saâda), der grosse Atlas (Djelfa), endlich bei Laghouat die eigentliche Wüste berührt, somit jedes Glied der geographischen Zusammensetzung des Landes besucht. Durch einen Abstecher nach dem höchsten Theil des algerischen kleinen Atlas, dem bis $2308 \mathrm{~m}$ hohen, in der grossen Kabylie liegenden Djurdjura, hoffte ich eine echte Hochgebirgsfauna kennen zu lernen. Mangel an Wegen, Unterkunft und kundigen Führern vereitelten diesen Plan, und auch die Erwartung, dass das hochgelegene Aumale mit seiner gebirgigen Umgebung oder das in einer hügelreichen Vorlandschaft des Djurdjura liegende Bouira einige schwache Spuren alpiner Formen bergen möchte, wurde in keiner Weise bestätigt.

Die so durchmessene Route bildet in gewissem Sinne eine Parallele zu der früher verfolgten von Oran nach Aïn Sefra, nicht nur in der Hauptrichtung, sondern auch bezüglich der Beschaffenheit des Landes, mit dem Unterschied jedoch, dass die Steppenregion zwischen Saïda und Aïn Sefra bedeutend breiter ist als zwischen Boghari und Djelfa, dagegen die Kette des grossen Atlas zwischen Djelfa und Laghouat einen breitern Streifen als südlich von AïnSefra bildet.

Etwas anders liegen die Verhältnisse in den von mir im Monat Juni und den ersten Tagen des Juli des vergangenen Jahres berührten Gebieten Tunesiens. Zum Theil aus denselben Gründen wie in Algerien wählte ich abermals eine von Norden nach Süden führende Route und zwar zunächst der Küste entlang. Längere Zeit wurde der nähern und fernern Umgebung von Tunis gewidmet, mehrmals die Strecke von Marsa, Goulette, Carthago, ferner Hammamel-Lif und die Gegend des Bardo besucht. Gegen Süden wählte ich Hammamet und das benachbarte Bir bou Rekbah, Sousse, Sfax und endlich Gabès für einen dem Ergebniss der wissenschaftlichen Ausbeute entsprechenden längern oder kürzern Aufenthalt. Dabei musste sich zeigen, ob der noch zu erwähnenden Anreicherung der westwärts vorkommenden Fauna in der That die aus der Literatur zu entnehmende Verarmung der östlichen gegenüberstehe, ob die im algerischen Tell gefundenen Arten von dem Einfluss des Küstenklimas abhängig sind oder ob die Zusammensetzung des Artbestandes mehr von den Bodenverhältnissen beeinflusst wird. Die ost-tunesische Küste weicht bekanntlich in mehr als einer Hinsicht von der algerischen ab. Wohl trägt die Umgebung von Tunis noch vorwiegend den Charakter des Tell, schroffe Gebirge wechseln mit fruchtbaren Thälern 
und Ebenen ab, der Boden ist meist etwas lehmig, vielfach salzigimprägnirt; das Klima aber scheint schon mehr dem der Steppe ähnlich zu sein, die Maximaltemperaturen erreichen bis $48^{\circ} \mathrm{C}$., die um so drückender auf die Thierwelt wirken, als erfrischende Brisen selten sich erheben, die Luft wasserreich ist, ohne dass die Vegetation davon viel gewänne. Die Regenmengen fallen der ganzen Küste entlang spärlich. Gabès mit seiner so wasserreichen Oase leidet nicht selten schwer unter der Dürre, da befruchtender Regen oft über ein Jahr ausbleibt. Etwa von Sfax an erhält die Küste das Gepräge der Wüste. Schon in Sousse tritt die Gattung Eremiaphita, eine echte Wüstenbewohnerin, auf. Ist dort der Boden noch vorwiegend staubig-kalkig mit einer wechselnd starken Lehmbeimischung, so wird er bei Sfax, noch mehr bei Graïba ${ }^{1}$ ), sandig. In der Umgebung von Gabès endlich tragen weite Strecken einen sandig-lehmigen Boden mit starkem Salzgehalt, der nur eine einförmige halophile Vegetation aufkommen lässt und indirect auch auf die Fauna bestimmend wirkt. Auf den südlichen Erhebungen und den nördlich der Oase sich ausdehnenden Gebieten herrscht echter Wüstensand vor, damit ändern sich auch die Verhältnisse für die Organismen, trotzdem ist es auffallend, dass weder die Zahl der Arten noch die der Individuen auch nur annähernd die an algerischen Fundorten entsprechender Beschaffenheit beobachtete erreicht. Auch Sfax, Sousse, Hammamet sind nach meiner Erfahrung mit einer recht spärlichen Orthopterenfauna versehen. Dies ist aber wohl zum grossen Theil der umfangreichen und äusserst energisch betriebenen Bebauung des Bodens, besonders der Olivencultur, zuzuschreiben.

Nach dem ursprünglichen Plane sollte die Rückreise durch das Innere des Landes erfolgen, wodurch eine weitere werthvolle faunistische Parallele zum Vergleich gewonnen worden wäre. Die Umständlichkeit der Verkehrsmittel beanspruchte aber mehr Zeit, als mir zur Verfügung stand, weshalb ich mich mit einem Abstecher nach Gafsa, einer möglichst central im Süden Tunesiens gelegenen Oase, begnügte. Obgleich auch dort, abgesehen von der Oase und dem Culturlande, die Flora des sandigen, feuersteinreichen Bodens eine äusserst spärliche und karge ist, liefert die Fauna doch ein ganz anderes Bild als an den Küstenorten. Schon direct bei der Bahnstation begegnet man zahlreichen Acridiern und Eremiaphilen.

1) An der Linie der Phosphatbahn Sfax-Gafsa. 
Man wird an die bessern algerischen Fundplätze erinnert. Wenn auch die Artenzahl vielleicht geringer ist, so findet der Sammler dafür einen Ersatz in der Menge einzelner seltnerer Formen.

Auf beiden algerischen Linien sind die klimatischen und meteorologischen Verhältnisse so ziemlich dieselben. Tell und kleiner Atlas werden in der Regenzeit ganz auffallend reichlich mit Niederschlägen versehen, die von Osten nach Westen abnehmend bei Calle und Bougie annähernd $100 \mathrm{~cm}$, bei Oran aber nur etwa $45 \mathrm{~cm}$ betragen. Im Gebirge erhöhen sich diese, in Europa nur selten erreichten Zahlen noch um ein Beträchtliches. Das Steppengebiet zeichnet sich durch geringen Regenfall und sehr trockene Luft aus. Doch können auch dort selbst im Sommer noch ganz gewaltige Wassermengen niedergehen, die geradezu an tropische Wolkenbrüche erinnern. Mitte Juni wurden wir, auf der Postwagenfahrt nach Djelfa begriffen, am Nordabhange des grossen Atlas in der Nähe des Rocher de Sel von einem Unwetter überrascht, das ebenso schnell aufstieg, als es sich entlud und verschwand. Mit einem Donnerschlag einsetzend stürzten ganze Bäche aus den Wolken herab; bis der Kutscher vom Bock gestiegen, um seine Pferde zu halten, floss von dem schwach nach Sïden ansteigenden Terrain das Wasser ca. $10 \mathrm{~cm}$ hoch, jede Bodenrinne war mit einem wild tosenden Bach angefüllt; die Flut führte Massen von Insecten mit sich, vor Allem Schistocerca, Caloptenus und Pimelien. Nach 15 Minuten brannte die Sonne wieder, und kurz darauf schien der Boden mit Ausnahme einiger vertieften Stellen nahezu trocken, von der Sintfluthprobe kaum mehr eine Spur vorhanden zu sein. Ueber die Feuchtigkeitsverhältnisse im grossen Atlas ist mir nichts bekannt. Doch lässt die Armuth der Vegetation auf eine äusserste Spärlichkeit derselben schliessen, welche nur noch in der Wüste übertroffen wird. In Laghouat fällt insgesammt jährlich nur $45 \mathrm{~mm}$ Regen, an andern Orten bleibt auch dieser geringe Betrag über 12 Monate lang aus. Den Niederschlagsmengen ist der Feuchtigkeitsgehalt der Luft proportional, der somit von der Küste nach dem Innern zu rasch abnimmt, dort durch seinen hohen Betrag die keineswegs weit entfernten Extreme der T'emperatur - im Jahre etwa $0^{\circ}$ und $30^{\circ}$ C. - sehr unangenehm empfinden, hier dagegen, aufs Aeusserste reducirt, die oft enorm schroffen, täglich $25-35^{\circ}$ C. erreichenden Schwankungen verhältnissmässig leicht ertragen lässt.

In reichlichstem, wenn auch wegen der an der Küste häufigern Bewölkung nicht ganz gleichem Maasse spendet die Sonne dem Lande 
Licht und Wärme. Nach eigenen Messungen betrug die Temperatur in Laghouat am 10. Juni Morgens 10 Uhr $38^{\circ}$ C. im Schatten, die des sonnendurchglühten Sandes zur selben Zeit etwas unter der Oberfläche $50^{\circ} \mathrm{C}$. Zwischen Djelfa und Bouira zeigte im Juli das Thermometer Morgens 11 Uhr gewöhnlich zwischen 27 und $38^{\circ}$, Abends 8 Uhr 2-3 Grade weniger. Bei Dra el Mizane wurde einmal Vormittags $10 \mathrm{Uhr}$ in der Sonne $56,5^{\circ}$ C. abgelesen bei sehr feuchter Luft. Während einer Nachtfahrt zwischen Djelfa und Bou Saâda kühlte sich die Luft am 19. Juli auf $13^{\circ} \mathrm{ab}$. Sofort nach Sonnenuntergang sinkt auch die Temperatur des Bodens, besonders des Sandes, in Folge der Ausstrahlung auffallend schnell.

\section{Die Rolle des Windes für die Verbreitung der Arten.}

Im Gebiete der Steppe und Wüste spielt, geologisch genommen, der Wind die Rolle des Wassers, und nicht selten wirkt er für die Organismenwelt nicht weniger katastrophenhaft als dieses, vor Allem durch die Bewegung enormer Sandmassen, die bald gegen Felsen angeschleudert, diese langsamem Zerfall entgegenführen, bald alles überdeckend sich zu bergehohen Dünen aufthürmen. Von seiner oft Stunden, ja Tage lang ungemindert anhaltenden orkanartigen Wucht erhält man eine Vorstellung beim Ueberschreiten von Dünen- oder Hügelkämmen oder beim Anblick der in einem Viertelkreise sich davor beugenden schlanken Dattelpalmen. Dabei werden die schwereren Sandmassen auf oder nahe der Erde hingetrieben und drohen die fast ausnahmslos am Boden lebenden Orthopteren zu überschütten. Diese sind daher in ständiger Bewegung, die geflügelten erheben sich immer und immer wieder in die Luft, wo sie vom Winde erfasst Meilen weit getragen werden, besonders die Wanderheuschrecken Schistocerca und Stauronotus. Gar häufig mögen Arten so auf ungeeigneten Boden gelangen und dort untergehen, oder sie werden in die Chotts geworfen, an deren Rand, wenn sie Wasser enthalten, Unmengen von Cadavern angespült werden. Man sollte meinen, dass vermittels des Windes im Lauf der Zeit alle fliegenden Arten sich über das ganze Land verbreiten müssten, dass die nördlichen südwärts, häufiger jedoch die südlichen nordwärts transportirt würden, weil gerade im Sommer während der Ausbildung der Imagines heftige Wüstenwinde vorherrschen. Abgesehen davon, dass die schon erwähnten physikalischen und meteorologischen Bedingungen die Grenzen der meisten Arten mit Ausnahme der mehr oder weniger 
kosmopolitischen, bestimmen, wird deren Ausbreitung durch den Wind wesentlich in Folge des Bestrebens, gegen denselben zu fliegen, eingeschränkt. Immer schien es mir, als seien die Orthopteren der Wüste bei Nacht noch mehr vom Winde beunruhigt als am Tage; jedenfalls konnte das eben Gesagte am leichtesten auf einigen nächtlichen Postfahrten bestätigt werden. Die Wagenlaternen leuchteten nach drei Seiten. Vom Licht angezogen prallten Tausende von Heuschrecken, untermischt mit einigen Eulen und Schwärmern, vor Allem aber mit Myrmeleon-Arten, an der vordern Scheibe an, während der Wind auf der hintern stand. Die Hauptrolle in dem nächtlichen Laternentanz spielten 4 Sphingonotusarten und Caloptenus. Die beiden Wanderheuschrecken Schistocerca und Stauronotus, bekanntermaassen gute Flieger, lassen sich gerne mit dem Winde treiben, womit wohl auch die enorme Ausdehnung ihrer Wanderungen aus dem äussersten Süden bis an die Küsten zu erklären ist; beide Arten trafen mehr als die andern auf die hintern und seitlichen Scheiben. Die Geschwindigkeit, welche die mit dem Winde schwirrenden Exemplare erlangen, erreicht offenbar einen ganz bedeutenden Betrag, der sich ungefähr an der Wucht ihres Anpralls an festen Körpern abschätzen lässt. Beim Ueberklettern eines Hügelkammes nördlich von Djelfa, das des Sturmes wegen nur auf allen Vieren möglich war, prallte an dem aus Pflanzenmark bestehenden, stoffüberzogenen Sonnenhelm eine Eremobia cisti so heftig an, dass ein deutlicher Eindruck entstand, das Thier aber mit eingedrücktem Kopf niederfiel.

Endlich ist zu berücksichtigen, dass die meisten flugbefähigten Acridier sich nur wenige Meter über den Boden erheben und sich, selbst wenn sie in dieser Höhe vom Winde weit fortgetragen werden, bei den bisher ins Auge gefassten Windrichtungen von Norden nach Süden oder umgekehrt doch nur selten aus dem Gebiet ihrer Verbreitung entfernen, weil sie an dessen natürlicher Grenze, den Gebirgsketten, abgeladen werden: die Wüstenformen bei Südwind am Südabhange des grossen, die Steppenformen am Fusse des kleinen Atlas, bei Nordwind an den entgegengesetzten Seiten. Wie stark die Macht der Winde an den Bergen sich bricht, ersehen wir auch aus der Anhäufung der ungeheuren Dünen, die ihnen vorgelagert sind. Aus dem eben Gesagten ergiebt sich die durch die Thatsachen bestätigte Folgerung, dass die genannten Gebiete gewissermaassen einen unfreiwilligen Sammelplatz zahlreicher Arten und Individuen darstellen. Diesen Umständen ist es zuzuschreiben, dass in Laghouat, Biskra, 
Aïn-Sefra, Djelfa, Gafsa u. s. w., also stets an solchen Orten, welche an den der Hauptwindrichtung entgegenstehenden Bergketten liegen, auf kleinem Raum eine viel grössere Ausbeute gemacht wird als draussen in den unendlichen Flächen der Wüste und Steppe. Im Tell und Gebirge liegen die Verhältnisse anders. Dort fehlt der am Boden hinfegende Sand, und was vom Südwind weit verschleppt, allenfalls aus der Luft herabsinkt, ist ganz feinkörnig, kaum fühlbar, und auch davor könnten sich die Acridier hier leicht unter Steinen oder grössern beblätterten Pflanzen schützen.

Viel weniger einschneidend auf die Verbreitung der Thiere scheint der Ost- und Westwind zu wirken. Beide streichen annähernd parallel der geographischen Gliederung des Landes, und somit ist die Gefahr der Verschleppung in ein faunistisch fremdes Gebiet bedeutend geringer, wenigstens in Algerien. Im südlichen Tunesien mit seinem flachen Küstengebiet werden die fliegenden Arten rom Westwind leicht ins Meer getragen. Augenzeugen berichten, dass auf diese Weise das Land bei Gabès in kürzester Zeit von riesigen Schwärmen der Wanderheuschrecke vollkommen gesäubert worden sei.

Ein ganz auffallend grosser Theil der algerisch-tunesischen Orthopteren, etwa 97 Arten aus allen Abtheilungen und 37 Gattungen, also nahezu die Hälfte aller bekannten, ist durch weitgehende Verkümmerung oder gänzlichen Mangel der Flugorgane vor dem Transport durch den Wind geschützt, sowohl Bewohner der Küste als des Steppen- und Wüstengebiets. Trotzdem sind auch diese kaum weniger allgemein innerhalb der ihnen von Natur vorgeschriebenen Zonen verbreitet als die geflügelten. Zur Erklärung ihrer Ausdehnung kann der Wind nicht beigezogen werden, will man nicht annehmen, dass schon von den noch geflügelten Vorfahren der betreffenden Arten eine Invasion in die jetzt besetzten Gebiete stattgefunden habe und erst später die Verkümmerung der Flugorgane eingetreten sei. Es ist aber noch sehr fraglich, ob eine solche vorausgesetzt werden darf, ob nicht die jetzige Beschaffenheit und Grösse der Flügel eine ursprüngliche ist. Aber auch abgesehen davon wird man den gegenwärtigen Zustand bei dieser Frage im Auge behalten und annehmen müssen, dass seit Langem der wichtigere Theil der Ausbreitung per pedes erfolgt sei. Sind die meisten hierher zu rechnenden Formen auch nichts weniger als gute Fussgänger, so werden ihre Expansionsgelüste doch durch einen mehrfach beobachteten Wandertrieb und eine offenbar sehr grosse Anpassungsfähigkeit wesentlich unterstiitzt. 
Für die Beurtheilung der zu dieser langsamern Art der Ausbreitung nöthigen Zeit finden wir, wie später gezeigt wird, einige Anhaltspunkte; sie braucht nicht zu kurz bemessen zu werden. Die Vertheilung flugunfähiger Arten ist über das ganze Gebiet eine ziemlich mit der flugbefähigter übereinstimmende, nur findet man sie da, wo durch den Wind Anhäufungen der letzteren entstehen, nicht häufiger als sonst, - ein indirecter Beweis für das vorhin über die Bedeutung des Windes Gesagte.

\section{Verzeichniss der gefundenen Arten. ${ }^{1}$ )}

Weniger wegen des Reichthums an neuen Arten als vielmehr wegen der vielen von mir in den Monaten Juni-Juli berührten bisher gar nicht oder kaum oberflächlich untersuchten Oertlichkeiten und der vielfach dort beobachteten Localformen ist eine systematische Aufzählung der ganzen $1897 \mathrm{er}$ Ausbeute angezeigt. Da beide Reisen in dieselbe Jahreszeit fielen, wie die früher von ZeHntwen und mir in Oran unternommenen, ist ein directer Vergleich der darüber veröffentlichten Listen möglich. Wie gewöhnlich im Sommer, herrschen Acridier und Locustiden vor, dagegen treten die Forficuliden, Blattiden, Mantiden, Phasmiden und Gryllen theils wegen des frühern, theils wegen des spätern Abschlusses ihrer Entwicklung zurück.

\section{Forficulodea.}

\section{Labidura riparia (PALL.).}

1 q von Bou Saâda, 8./7. Ist im Allgemeinen mehr auf das Littorale beschränkt; aus Bou Saâda noch nicht erwähnt. Gabès 15. 6. 01 ; gemein.

\section{Anisolabis mauritanica (Luc.).}

Blidah 1 \& 1 Larv., 16.|6.; Aumale 1 \& 2 Larv., 14.7.; Medeah 2 of 2 Larv., 18.6. Aus dem Innern noch nicht bekannt, offenbar der ganzen Küste entlang verbreitet. Tunis 9.6. 01. Gabés 1 , 17.6. 01 .

1) Mit wenigen Ausnahmen wurde in diesem Verzeichniss die von Finot (1. c.) gewählte Reihenfolge der Arten und Gattungen und auch die Nomenclatur beibehalten. Wegen der Synonyme verweise ich ebenfalls auf diese Abhandlung, sofern keine Aenderung oder Vervollständigung nöthig war. 


\section{Forficula auricularia L.}

Neu für Tunesien; am Rande der Sebkha Seldjoumi bei Tunis ช ๆ, 9.6. 1901.

\section{Forficula pubescens GÉNÉ.}

Bisher nur i. l. von Bonmans aus Algier ohne genaue Fundortsangabe genannt. Fundort: Medeah, đ, 15.6. 97.

\section{Forficula sp.}

Eine nicht sicher bestimmbare, der $F$. ruficollis FABr. nahestehende Larve von Medeah, 15.6. 97.

\section{Blattodea.}

\section{Heterogamia africana (L.)}

3 offenbar erwachsene $11 \mathrm{~mm}$ lange qo stelle ich mit Vorbehalt hierher. Thre Farbe ist ein lichtes Gelbbraun. Die ganze Rückenseite ist schwach mit ganz kleinen Härchen besetzt. Die Hinterränder der Segmente tragen einen zarten Saum davon. Lange ziemlich dicht stehende Haare zieren den ganzen Aussenrand der Pronotumsegmente und, weniger dicht, die Abdominalseiten, die ganzen Beine mit dem ersten Tarsalglied und die Bauchseite. Kopf hellbraun, etwas dunkler zwischen den Fühlern und auf der Stirne. Pronotum etwas mehr nach vorn verschmälert als bei $H$. syriaca, Körper ein wenig schlanker. Alle Tibien sehr stark mit braunrothen Stacheln besetzt, besonders am distalen Ende. Hintertibien gebogen, in der Mitte des Aussenrandes mit 5 z. Th. neben einander gestellten Stacheln, im letzten Drittel des Innenrandes deren 3, am Ende aber 7, deren grösster der Innenseite entspringt und das erste lange Tarsalglied ein wenig überragt.

Von Finot ist nur die $H$. aegyptiaca (L.) und $H$. livida Br. aus dem Gebiete erwähnt, zu welcher ich die Art sicher gerechnet hätte, wenn nicht die Beschreibung Brunner's und die Abbildung davon im Prodromus fig. 12 B eine Species mit stark behaartem Pronotum, mit annähernd geraden, der doch so ausserordentlich stark hervortretenden Stacheln gänzlich entbehrenden Hintertibien zum Gegenstand hätte. Finot (p. 77) hebt als besonderes Merkmal seiner livida die gruppenweise Anordnung der Stacheln in der Mitte der 
Aussenseite der Hintertibien hervor, bei Brunner ist dies aber nur für $H$. africana $L$. angeführt. Ich vermuthe darum stark, dass auch Finot nur diese, auch aus Aegypten und Syrien, bekannte Art vor sich hatte, um so mehr als sie Krauss ${ }^{1}$ ) von Monastier erwähnt.

Fundort: Graïba (Bahnstation in der Nähe von Sfax) unter Steinen, 19.6. 01.

\section{Loboptera decipiens (GERM.).}

Blidah, 13. 7.; * Tunis ${ }^{2}$ ), 9.6. 01, 2 q .

8. Periplaneta americana (L.).

Algier, Juni 97, 1 ๙ ad.

\section{Mantodea.}

\section{Eremiaphila denticollis LUCAS.}

Das ठ dieser häufigsten der bis jetzt beschriebenen algerischen Eremiaphilen kennt man noch wenig. Fıмот giebt nach einem defecten Exemplar 12 mm Körperlänge an. Die von mir gesammelten 19 ठठ messen aber zwischen $19-23 \mathrm{~mm}$, wovon $3,8-\tilde{\mathrm{o} m}$ auf das Pronotum entfallen, dessen Oberfläche und Seitenränder genau wie die des $q$ beschaffen sind. Das Abdomen ist nur $5 \mathrm{~mm}$ breit, auf der Mitte des Hinterrandes des 3-7 Abdominaltergits stehen wie beim $q$ deutliche dornenähnliche Erhebungen. Die Flügel des $\delta$ sollen nach Finот grösser als die des $q$ sein. Im Durchschnitt aber sind sie kleiner, selten gleich gross. Eine Ausnahme macht nur ein $\delta$ aus Laghouat, dessen Elytren $9 \mathrm{~mm}$ lang sind und die breiten mit einem dunkeln in der Mitte unterbrochenem Schrägband versehenen Flïgel nur wenig überragen. Im Uebrigen sind die Finot'schen Zahlen für die Längen der Elytren ( § $3,5 \mathrm{~mm}$, q 3,5 mm) auffallend nieder. Meine Messungen ergeben für die Elytren der q von Djelfa 5,8-7 mm, im Durchschnitt $\mathbf{6 , 5} \mathrm{mm}$, für die männlichen 5,5-6,5 mm, im Durchschnitt $5,7 \mathrm{~mm}$, für $q$ von Gafsa 6,5 bis $9 \mathrm{~mm}$, für $\left.\delta 5-6 \mathrm{~mm}^{3}\right)$, d. h. Maasse, welche sich mehr den für

1) Krauss, H., Dermapteren und Orthopteren aus Tunis, in: Wien. entomol. Z., Jg. 11, Hft. 5, 31. Mai 1892.

2) An den mit Sternchen versehenen Orten wurde die Art schon früher gefunden, die andern Localitäten sind neu.

3) Gemessen an 25 of und 15 ठठ 
E. numida angegebenen nähern. Auch die Zahlen über die übrigen Ausmaasse der $q$ sind zu erweitern. Die Körperlänge schwankt an dem untersuchten Materiale zwischen 23 und $28 \mathrm{~mm}$ (Fэмот 14-25); die Länge des Pronotums zwischen 4 und $5 \mathrm{~mm}(3)$, die Breite des Abdomens erreicht 10-11 mm (7). Die Farbe der meisten Exemplare ist eine licht gelblichbraune, mit dem Boden übereinstimmende, die Unterseite des Körpers und der Gliedmaassen aber beinahe weiss. Von Abzeichen ist nur die dunklere Ringelung der Beine constant zu bemerken. Ein Exemplar von Bou Saâda und eine weibliche Larve von Djelfa ist durch zahlreiche dunkle Punkte auf der ganzen Oberseite nebst Elytren ausgezeichnet, welche zwischen den Augen in 2 Querlinien angeordnet sind, auf dem Pronotum 3 Längsstreifen, auf dem Abdomen aber deren 5, 1 medianen und je 2 seitliche, andeuten. Auch 3 qf von Djelfa zeigen auf dem Abdomen noch stark hervortretende schwarze Punkte, besonders am Hinterrand der Segmente.

Fundorte: Bou Saâda 7.7. 97, Djelfa (im Westen sehr gemein 29.6. und 3.7., Guelt es Stel 13.6., Laghouat 24.6., Sousse 11.6. 01, Graïba 19.6., Gafsa 20.-22.6., Gabès 16.-19.6.

Finot vermuthet p. 95 (39 d. Sep.), dass Krauss unter dem Namen der E. spinulosa das ơ der E. denticollis beschrieben habe und dass wohl alle Arten der Gattung nur Localformen einer Art seien.

Gegen den ersten Punkt ist einzuwenden, dass, ganz abgesehen von den übrigen durch Krauss genau hervorgehobenen Unterschieden, die Hüften der Fangbeine von E. spinulosa ebenso wie die der $E$. mumida auf der Innenseite stets mit einem grossen dunkeln Fleck versehen sind, die der E. denticollis aber nie. Diesen dunkeln Fleck kann man, wenn auch weniger scharf begrenzt, schon bei Larven von 8-10 $\mathrm{mm}$ zur Unterscheidung benützen. Ob er auch bei $E$. barbara BBIs. vorkommt, ist aus deren Beschreibung nicht zu entnehmen; die $E$. denticollis ist somit bis jetzt neben der $E$. moreti aus der West-Sahara die einzige Art, der er sicher fehlt, und nicht auf jene, sondern, wie Krauss genügend betonte, auf E. mumida weisen die verwandtschaftlichen Beziehungen hin.

Die Möglichkeit der Bildung von Localformen lässt sich nicht in Abrede stellen bei einer Gattung, die, wie Eremiaphila, wegen des mangelnden Flugvermögens so ungemein an den Boden gefesselt ist und trotz der Behendigkeit im Rennen und der Bewehrung der Vorderbeine genöthigt ist, sich aufs Genaueste der Umgebung an- 
zupassen. Gleichwohl lassen sich meiner Ansicht nach die algerischen Arten nicht als Localformen bezeichnen, wenigstens nicht als von einer Art stammende. Dagegen spricht einmal das gemeinsame Vorkommen zweier Arten an der gleichen Localität (z. B. E. mumida und E. denticollis bei Laghouat und Biskra), sodann die Zahl und Beständigkeit der zur Unterscheidung benutzten Merkmale, von denen das eine, das Auftreten oder Fehlen des schwarzen Fleckes an der Innenseite der Vorderhüften, eine Spaltung der Arten in zwei Gruppen andeutet. Zudem lässt die enorme Ausdehnung des Verbreitungsgebietes auf ein so hohes phylogenetisches Alter schliessen, dass man die Arten der Gattung, selbst wenn sie erst aus Localformen entstanden, doch jetzt als wohl fixirt und scharf gesondert ansehen muss, was sich leicht durch die Uebereinstimmung von Vertretern einer Art aus verschiedenen Fundorten feststellen lässt. Die $E$. denticollis zeigt abgesehen von der wie gewöhnlich etwas wechselnden Grösse und Färbung an physikalisch recht verschiedenen Plätzen stets dieselben Nerkmale, ebenso die E. mumida und dasselbe wird sich auch für die seltenern Arten E. barbara und spimulosa noch nachweisen lassen. Das oben als Ausnahme angeführte $\delta$ von Laghouat gehört vielleicht einer andern, wohl neuen, Art an. Nicht nur die Flügel sind verlängert, sondern auch die Beine; das Femur des 2. Beines misst bei $E$. denticollis höchstens $8 \mathrm{~mm}$, die Tibia 7, bei dem zweifelhaften Thier 8 und 7,8, die entsprechenden Zahlen vom 3. Beine sind 10 und 11,5 wieder in maximo bezw. 12 und $13 \mathrm{~mm}$. Dabei ist das Pronotum nur 4,5 mm lang und dem der erstgenannten Art ungemein ähnlich. Leider ist das einzige Exemplar ganz frisch gehäutet, so dass weitere Kennzeichen nicht mit Sicherheit festzustellen sind.

\section{Eremiaphila numida DE SAUSS.}

Das Männchen dieser, bis jetzt nur von Biskra bekannten, durch das glattere Pronotum, die glattern Elytren, den dunkeln Coxalfleck der Fangbeine leicht von der vorhergehenden zu unterscheidenden Art gleicht dem Weibchen sehr. Long. corp. $=14-16 \mathrm{~mm}$, Long. pronot. $=3,5 \mathrm{~mm}$; Lat. pronot. $=3,5 \mathrm{~mm}$; Long. elytr. $=$ 3,2-3,6 mm, Lab. abd. $=4,5 \mathrm{~mm}$. Das Pronotum aller 3 gefangenen reifen Männchen verjüngt sich nach rückwärts weniger stark als beim $q$, die Sculptur seiner Oberfläche sowie der Mangel einer Bezähnelung der Seitenränder entspricht der für das $q$ gegebenen Beschreibung. Die Krallen, von denen die äussere grösser 
als die innere sein soll, finde ich durchweg gleich und zwar in beiden Geschlechtern.

Fundorte: Laghouat 20.-27.7. (häufiger als E. denticollis), 30 Larven, wovon mehrere im vorletzten Entwicklungstadium

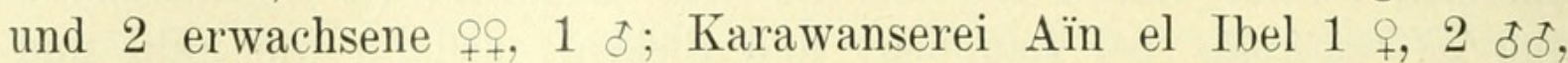
3 Larven.

Die Geschlechter lassen sich schon bei verhältnissmässig jungen Larven leicht unterscheiden, schon deshalb, weil das Abdomen der $\delta \delta$ stets schlanker als das der fo ist.

\section{Mantis religiosa $\mathrm{L}$.}

Wird nach den bisherigen Angaben offenbar erst sehr spät reif (September bis November); nur als Larve angetroffen, trotz der frühen Jahreszeit aber schon direct vor der letzten Häutung stehend. Die Larven sind der von Fischeria ungemein ähnlich, aber stets durch den Mangel irgend eines Abzeichens auf dem theils satt, theils licht strohgelb gefärbten Körper und den charakteristischen dunkeln Fleck auf der Innenseite der Coxa der Fangbeine davon unterschieden. Durch die Uebereinstimmung ihrer Farbe mit dem Aufenthaltsort (dürres Gras, Stoppeln) sind die Thiere nur schwer zu sehen, sie sind der dürren Jahreszeit gut angepasst. Da der Abschluss der Entwicklung mit dem Beginn der Regenzeit und damit der wiedererwachenden Vegetation zusammenfällt, ist zu erwarten, dass auch aus den gelben Larven grüne Imagines entstehen können. Beobachtungen darüber könnten einen werthvollen Beitrag über die Farbenwandlungen bei Insecten liefern.

Fundorte: Aumale 7. 97, Dra el Mizane 7. 97, Medeah 6. 97. Die Art scheint mehr auf die Küstenzone beschränkt zu sein, auch in Tunesien.

\section{Fischeria baetica (RАмв.).}

Diese weitverbreitete Mantide ist bislang mehr aus den westlichen Küstenstrichen und aus Tunesien bekannt. Die Larven sind denen der Mantis religiosa sehr ähnlich, gewöhnlich aber dunkler, fast bräunlich gefärbt und mit grauschwarzen Abzeichen - mehr oder weniger deutlichen Längslinien, besonders auf dem Abdomen versehen. An ganz hellen strohgelben Individuen verschwinden diese oft gänzlich bis auf eine sich erhaltende Andeutung der Mittellinie auf dem Pronotum. Einzelne erwachsene Männchen von Dra el Mizane sind ebenfalls ganz lichtgelb gefärbt, fast ohne Spur 
der sonst zu bemerkenden dunklern Töne auf den Elytren. Gewöhnlich wird die Art erst gegen Ende des Sommers reif, in Laghouat aber traf ich schon Ende Juni ausgewachsene $\delta$ und $q$ neben Larven. Die oठ sind seltener.

Fundorte: Aumale 13.7.; 4 क्ष, 1 ठ (auf den südlichen Bergen),

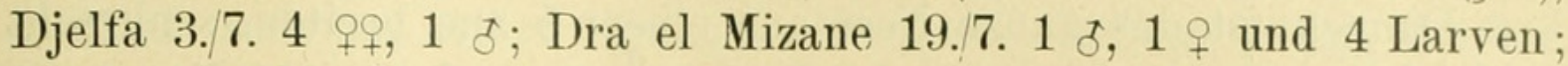
Laghouat 22.--24.6. 2 ๆ , 2 ठठ, 2 Larven. In Tunesien sehr verbreitet, aber mit Ausnahme eines q von Graïba, 1901 nur Larven gefunden.

\section{Eiernest von Ameles spallanaania (?) (Rossi).}

Ein an einem Stein bei Tunis angeheftet gefundenes Eiernest gehört einer der wenigen Arten dieser Gattung an, stimmt am meisten mit der von Giardina für $A$. spallanziana gegebenen Beschreibung und Abbildung überein. ${ }^{1}$ ) Weder von Brunner noch von Finot oder Krauss ist die Gattung aus Tunesien angeführt, dieses eine Stück also bislang die erste und einzige einigermaassen sichere Spur derselben von dort.

\section{Iris oratoria (L.).}

Eine Larve bei Gafsa 21.6. 01 angetroffen.

\section{Idolomorpha longifrons DE SAUSS.}

Neben einer noch ziemlich jungen, aber unverkennbaren Larve wurde südlich von Laghouat 24.7. 97 ein + auf Stoppeln erbeutet, denen die Farbe vollkommen entsprach. Ausser Biskra kannte man früher nur zwei Fundorte dieser seltenen Art aus Tunis.

\section{Eiernest einer Mantide (Idolomorpha?).}

Taf. 17, Fig. 1.

Ein sehr interessantes, wohl noch nicht beschriebenes Eiernest einer Mantide fand ich Ende Juni 1897 bei Laghouat an einem Stein angeklebt. Es stellt eine ovale Platte von $15 \mathrm{~mm}$ Länge, $10 \mathrm{~mm}$ Breite und $5 \mathrm{~mm}$ Dicke dar, deren Oberseite leicht eingedrückt ist, deren unterer Umfang den obern ein wenig übertrifft. Seine Construction ist ganz eigenartig und giebt einen klaren Auf-

1) Giardina, A., Sulla biologia delle Mantidi, in: Giorn. Soc. Sc. nat. econom., V. 22, Palermo 1899, tab. 1, 2. 
schluss über die Art der Herstellung. Wie die Fig. 1 zeigt, ist die Oberfläche von zahllreichen Linien durchquert, einer Anzahl von Lamellen mit Zwischenräumen entsprechend. Wie diese Structur zu erklären ist, ersieht man am besten an dem vordern, tadellos erhaltenen Ende.

Danach ist das ganze Nest aus einem $5 \mathrm{~mm}$ breiten, senkrecht auf der Unterlage stehenden, in der bekannten schaumigen Masse die Eier einschliessenden Streifen hergestellt, welcher in enge, vorn und hinten kürzere Falten gelegt ist. An unserm Stück sind 11 solcher fest verkitteter Falten zu zählen, deren Umbiegungen an den obern Seitenrändern mehr oder weniger frei zu sehen sind. Der ganze Streifen besteht offenbar aus zwei unten verbundenen Seiten oder Blättern. Entsprechend dem äussern Aufbau liegen die grossen, senkrecht stehenden Eier in Querreihen zu 3-6 neben einander; sie füllen das ganze Innere, sitzen in einer Art zarthäutiger Waben. Die an der Peripherie sind nur durch eine dünne Wand geschützt. Die obern Ränder der Blätterfalten sind leicht nach rückwärts verstrichen, so dass sie sich über einander legen. Die Farbe ist ein lichtes Rothbraun.

Form und Structur dieses Nestes sind von denen der bekannten sehr verschieden und ganz eigenartig. Klarer als bei andern Arten kommt der Grundriss an einander gerückter Schlangenlinien zum Ausdruck ${ }^{1}$ ), die offenbar durch die von Brogniart ${ }^{2}$ ) beobachteten regelmässigen Bewegungen des Abdomens erzeugt werden, während des Austritts der noch nicht erhärteten Masse aus dem Genitalapparate des eierlegenden Weibchens. Der ganze Aufbau wird noch weniger als bei den Ameles- und Mantis-Arten durch eine schaumige Umhïllung verwischt. Die Erzengerin des Nestes hat jedenfalls bei $p$ der Abbildung begonnen und dieses Stück an einen kleinen Vorsprung des Steins angeklebt. Dem Fnde des Geleges zu werden die Falten lockerer, ihre Umrisse deutlicher $(a)$. Die Eier waren alle ausgeschlüpft; aber nur an wenigen Stellen bemerkt man die Aus-

1) Zum Nest der Empusa pauperata Latr. bemerkt Giardina: Anzi si può asserire che il nido dell' Empusa ci presenti la conformazione fondamentale del nido della Mantis con una semplicità ed evidenza quasi schematiche.

2) Brogniart, CH., Observations sur la manière dont les Mantes construisent leurs oothèques etc., in: Ann. Soc. entomol. France (6), V. 1, 1881, p. 451, lässt weiterhin die Elytren und Cerci bei der Formung des Eiernestes von Mantis religiosa L. in Thätigkeit treten. 
trittsstelle der Larve $(A)$, gewöhnlich scheint dieselbe zwischen den aus einander gepressten Blättern der Querlamelle hervorzukommen.

Als Urheberin des kleinen Kunstwerkes können nur wenige Gattungen und Arten in Betracht kommen. Keine derselben kann in den besuchten Gegenden häufig sein, da sonst ebenso wie von den weniger seltenen Arten dasselbe Eiernest öfter gefunden worden wäre. So glaube ich Eremiaphila, Mantis, Fischeria, Ameles und Empusa ausschliessen zu dürfen. Discothera, Oxythespis sind in Algerien noch nicht gefunden worden. Mit einiger Wahrscheinlichkeit würde es sich somit nur um die Gattungen Heterochaeta, Hierodula, Blepharis und Idolomorpha handeln, von welchen aber die zweite bis jetzt nur von der Küste bekannt ist. Heterochaeta und Blepharis leben wohl im Gebiete der Wüste, fehlen aber bis jetzt aus Laghouat und Umgebung. So bliebe schliesslich nur die Empusa-ähnliche Idolomorpha übrig; welche dort von mir als Larve und Imago gefunden wurde.

\section{Acridiodea.}

\section{Paratettix meridionalis (RАмв.).}

Kommt im Flussbett des Oued Bou-Saâda zusammen mit Tridactylus vor, ist aus dem Süden Algeriens noch nicht erwähnt.

Fundorte: Blidah 16.7. 3 of, 1 б; Dra el Mizane 17.7. $1 \delta$; Aumale 14.7. 9 ठં, ๆ; Bou Saâda 8.7. 21 ठ, $q$; dies ist wohl der südlichste bis jetzt in Algier bekannte Fundort.

\section{Acrida (Truxalis) unguiculata RАМв.}

Seltsamer Weise wurden 1897 gar keine entwickelten Thiere, und auch von den sonst häufigen Larven nur wenige angetroffen, von welchen die aus Laghouat noch sehr klein sind.

Fundorte: Dra el Mizane, Juli. 2 Larv.; Aumale 11.7. 2 Larv.; Laghouat 20.6. 2 Larv.; Tunis $2 \delta \delta, 1$ †, 10.6. 01; Hammam el Lif 2 ठठ, 28.6.; Bir bou-Rekbah 2 ठठ, 26.6.; Gabès 2 ठठ, 2 के, 15.6.; Gafsa 8, 22.6.

Das of schnarrt laut und rauh, beim Fliegen rasseln beide Geschlechter, wenn auch nicht sehr stark.

17. Ochrilidia tibialis (FIEв.).

Laghouat 20.6. 97. Früher nicht südlicher als Biskra angetroffen, aber 1894 von mir bei Aïn Sefra und Tiont nachgewiesen. 
18. Duronia (Phlaeoba) lucasi BoL.

Die tunesischen Exemplare sind etwas schlanker, die $\delta \delta$ kleiner als die algerischen, alle + ? grün an Kopf, Pronotum und Hinterschenkel, ebenso am Rücken des Abdomens und im vordern (Mediastinal-) Feld der Elytren; die ठठठ dagegen gleichmässig braun. Die Länge der Elytren ist ein wenig variabel, auch beim o (cf. Finot p. 418).

Fundorte: Gafsa 21./6. 01 (q gross, Flügel verkürzt), Gabès 17./6. Steht der Duronia fracta Fieb. aus Ephesus sehr nahe, ist aber viel kleiner und zierlicher als diese, die Fühler sind kürzer, die Flügel weniger dunkel getont.

\section{Epacromia strepens (LATR.).}

Weit verbreitet, doch nie häufig, vorwiegend auf die Küste beschränkt. Der südlichste bis jetzt bekannte Punkt des Vorkommens in Algerien ist Aïn Sefra (Mai 94); Bouira 16.7. 1 ठ; Dra el Mizane 17. 7. 1 ठ.

\section{Stenobothrus pulvinatus (FISCH.-WALDH.)}

Verbreitung ähnlich wie bei der vorhergehenden Art, bisher ebenfalls aus dem Süden noch wenig bezw. gar nicht bekannt gewesen.

Fundorte: Aumale 11.7. 2 qक; Bouira 16.7. 3 co, 1 ๘; Medeah 15.6. 1 \%; Dra el Mizane 17.7. 1 \%, 1 б; Blidah 13.6. 1 б; Laghouat 24.6. 2 ठठ

\section{Stauronotus maroccanus (THunB.).}

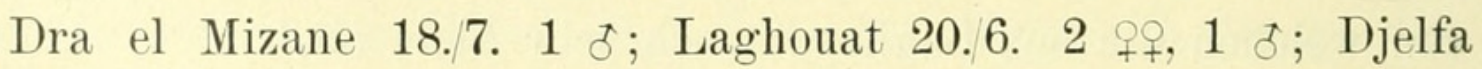
29.6. 2 क⿱ 1 ठ 1 .

\section{Stauronotus genei (OCsKAY).}

Die Färbung ist sehr veränderlich; der obere Theil der Elytren oft fast schwarz (Dra el Mizane, Aumale, Bouira), oft gelblich weiss, welche Farbe sich dann in einen breiten Mittelstreifen über das Pronotum fortsetzt (Laghouat, Bou Saâda, Dra el Mizane), oder grünlich (Bouira). Die Art kommt sehr häufig in Gesellschaft mit Egnatioides (S. 361) vor, derart, dass man sie in den Fundorten desselben erwarten kann. 
Fundorte: Bouira 16./7. 4 के; Aumale 9.-11.7. 5 \%о, 4 ठठ;

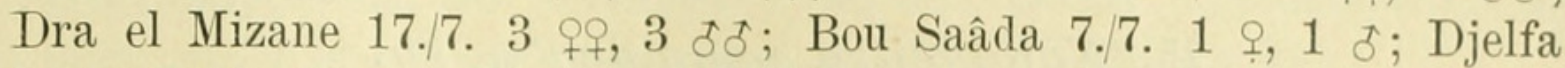

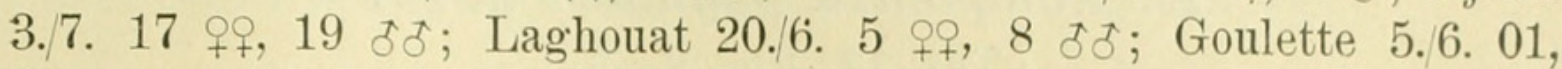
Hammam el Lif 26.6., Bir bou-Rekbah 26.6., Sousse 12.6., Sfax 23.6., Gafsa 22.6., Graïba 19.6.

Gewöhnlich findet man sie auf eng begrenzten Bezirken, gewissermaassen Inseln, in grösserer Anzahl beisammen, zwischen denen oft weite Strecken vollkommen frei davon sind. Diese Art des Vorkommens hängt durchaus nicht mit irgend welchen localen Verhältnissen (Pflanzenwuchs, Beschaffenheit des Bodens) zusammen, wie bei Bou Saâda, Djelfa und Laghouat, ebenso an allen tunesischen Plätzen mehrfach festgestellt werden konnte.

\section{Eremogryllus hammadne KRAUss.}

(Taf. 17, Fig. 4.)

Eremogryllus hammadae Krss., in: Verh. zool.-bot. Ges. Wien, V. 52, 1902.

Mitten in der Wüste zwischen Tuggurt und Onargla fand Krauss dieses kleine, durch sein helles, starkes Zirpen auffallende Thierchen zum ersten Male. In mehreren Exemplaren, darunter auch Larven, traf ich es auf den südlichen Dünen bei Gafsa an, genau so gelbröthlich wie der Sand gefärbt. Trotz reichlich einstündiger Beobachtung war kein Laut von demselben zu vernehmen. An andern vollkommen ähnlichen Plätzen fehlte die Art; sie war auf einen Raum von kaum mehr als $100 \mathrm{~m}$ Durchmesser beschränkt.

Fundort: Gafsa 21.6. 01; ferner El Mreir (Algerien), coll. BRUNner.

\section{Notopleura saharica Krauss.}

Notopleura saharica Krss., in: Verh. zool.-bot. Ges. Wien, V. 52, 1902.

Wie die vorhergehende Art ebenfalls erst einmal von Krauss in der Wüste gefunden, geht noch weiter nördlich als diese und lebt an der Peripherie des grossen, an die Mauern von Sfax sich anschliessenden Begräbnissplatzes, auf und zwischen dessen Gräbern ich 2 Pärchen 23.6. 01 erhielt. Brunner's Sammlung enthält $1+$ aus Aîn Sefra (Oran). 


\section{Notopleura pygmaea n. sp.}

Taf. 17, Fig. 2-3).

Der vorhergehenden Art, in einzelnen Punkten auch Eremogryllus hammadae KRss., sehr nahe stehend, aber kleiner und schlanker. Farbe gelblich-braun mit dunklern Abzeichen. Kopf mit den Merkzeichen der Gattung, Stirnleiste sich zwischen den Fühlern verbreiternd, flach, dunkel punktirt, mit unterhalb der Ocelle divergirenden scharfen Seitenkielen, Stirngrübchen trapezförmig. Vom Kopfgipfel bis zum Hinterhaupt verläuft eine mediane helle, seitwärts je von einer dunkelgrau punktirten Binde begleitete Linie, welche sich über das Pronotum fortsetzt. Etwas oberhalb der hintern Augenmitte je ein beller Fleck, nach unten von einer dunkeln Binde begrenzt. Antennen viel kürzer als Kopf und Pronotum zusammen, gegen das Ende schwach verdickt und tiefer als im Anfang gefärbt, 23 gliedrig, die letzten 8 Glieder sehr verkürzt. Pronotum wenig eingezogen, nicht gedrungen, der Hinterrand weniger stark abgerundet als bei Eremogryllus, wie bei diesem je 2 gelbe Fleckchen direct am Vorderrand und hinter der Hauptquerfurche, je einem solchen auf den Seitenlappen, alle von etwas verwaschenen Spuren von dunkeln Längsbinden umgeben. Hauptquerfurche schneidet den deutlichen, aber schwachen Mittelkiel vor der Mitte; die 2 vordern Querfurchen etwas undeutlich auf der Prozone, erreichen den Mittelkiel nicht. Seitenlappen etwa so hoch wie lang, ihr Unterrand schräg mit abgerundeten Winkeln; Seitenkiele fehlen an der Prozone des Pronotums, sind auf der Metazone, schwach divergirend, kaum angedeutet. Elytren (Fig. 2) das Abdomen nicht überragend, linear, schmal, mit sehr einfachem Geäder und unregelmässig vertheilten dunklern, in der Mitte der Felderchen sitzenden Punkten, besonders zwischen den Radial- und Ulnaradern. Radialadern nicht verzweigt, Stigma kaum angedeutet, Ulnarader fast gerade, Axillarader frei. Flügel hyalin, gelblich, mit einigen dunklern Adern.

Meso- und Metasternum (Fig. 3) gedrungen, breit, von rundlichem Umrisse, ebenso wie der kurze, aber sehr breite, ein gestrecktes Rechteck bildende Kropf wesentlich von Eremogryllus hammadae verschieden (vgl. Fig. 4). Hinterschenkel nicht sehr schlank, oberseits mit 3-4 braunen Flecken, Tibien blau, mit leicht gebogenen, theils behaarten, sehr langen Enddornen, deren unterer das erste Tarsalglied überragt. Cerci so lang wie dick, die Theile des äussern 
Genitalapparats mit vertieften Punkten; untere Vaginalplatten mit einer einfachen Querfurche, ohne äussere Seitenzähnchen.

$$
\begin{array}{cccc} 
& & \multicolumn{2}{c}{{ }^{q}} \\
\text { Länge des Körpers } & 14 & \mathrm{~mm} \\
" & 2,5 & \text { Pronotums } & 2,5 \\
" \quad \text { der Elytren } & 10 \quad " & \\
" \quad \text { Hinterschenkel } & 8 \quad "
\end{array}
$$

Unterscheidet sich von $N$. saharica hauptsächlich durch geringere-Grösse, dünnere Antennen, Mangel der Seitenkiele auf der Prozone des Pronotums, sehr schmale, jeder Verbreiterung entbehrende Elytren und deren reducirte Aderung, längere Enddornen der Hintertibien und endlich durch die Abwesenheit der Seitenzähnchen an den untern Vaginalplatten.

Obwohl der Beschreibung nur ein Exemplar zu Grunde lag, das o noch nicht bekannt ist, glaube ich doch, dass die Art leicht erkannt werden kann. Wie die 2 vorhergehenden gehört sie wohl ausschliesslich der Wüste an und wurde im Sande südlich von Gabès 15.6. 01 gefunden.

Die Artenzahl der Stauronotus-ähnlichen Formen scheint nach Süden zuzunehmen. Während Brunner für Europa nur 4 Arten kennt, wovon aus den Küstengebieten Algeriens und Tunesiens nur 2 nachgewiesen waren, kommen nun aus den südlichen Theilen nicht weniger als 3 neue hinzu, alles zierliche, kleine, dem Wüstenboden angepasste Gestalten.

\section{Stethophyma hispanicum (RАмв.).}

Auch diese Art geht viel weiter nach Süden, als bislang bekannt war, und wurde von mir noch um Laghouat gefunden. Die Rosafärbung des Basilartheils der Flügel ist aber bei den von dort stammenden Weibchen bis auf eine schwache Spur, bei den Männchen vollkommen verschwunden, die schön orangerothe Färbung der Unterränder der Schenkelinnenseite bis auf einen schwach gelblichen Ton verblasst, ebenso das Blau der Hintertibien.

Fundorte: Dra el Mizane 9.7.; Laghouat 27.6.

\section{Oedipoda gratiosa SERV.}

Bei einigen Exemplaren von Bouira und Djelfa sind die Elytren gegen das Ende zu grünlich überhaucht. Die Flügel, ursprünglich 
bis zur schwarzen Binde lebhaft rosenroth gefärbt, werden in Süden mit Ausnahme von Gabès blasser (Djelfa), was sich auch nachträglich an den früher bei Mecheria in Oran gefangenen Thieren bestätigen liess. Das Roth ist in der Nähe der Adern und Aederchen intensiver, in der Mitte der von diesen umgrenzten Felderchen beginnt der Farbstoff zu verschwinden; so entsteht eine Art weiss-rother Marmorirung. Sehr häufig tritt die schwarze Binde am Hinterrand zurück.

Der hintere, von der Hauptquerfurche und den Seitenkielen begrenzte Abschnitt des Pronotums einiger Exemplare von Bir bou Rekbah ist schneeweiss und dann mit Ausnahme des Mittelkiels vollkommen glatt. Häufiger findet man denselben Theil dunkel sammtschwarz gefärbt von normaler höckriger Oberfläche.

Fundorte: Aumale 10./7.; Bouira 16./7.; Dra el Mizane 17./7.; Bou Saâda 5./7.; Djelfa 3./7.; Laghouat 20./7.; Tunis 9./6. 01; Bir bou Rekbah 26.6. gemein; Hammam el Lif 26.6. ebenso; Sousse 12./6. neben 5 reifen ơ noch junge Larven; Sfax 23.6.; Gabès 15./6. selten Flügel kräftig roth.

\section{Oedipoda fuscocincta LUC.}

2 ठठ von Blidah aus dem Kies des Oned el Kebir sind genau wie das Gerölle grau gefärbt, alle andern Thiere schmutzig gelblich, ein $\delta$ von Djelfa fast strohgelb.

Fundorte: Aumale 10.7.; Dra el Mizane 19./7.; Blidah 13.6.; Hammam el Lif 26.6. 01.

\section{Oedipoda coerulescens L. var. sulfurescens SAUSS.}

Die Stammform wurde offenbar bis jetzt in Algerien nicht angetroffen, auch von mir weder dort noch in Tunesien, von wo sie Finот aufführt. Die Varietät scheint mehr auf die Küste beschränkt zu sein. Die Flügel der meisten Exemplare sind weniger citronengelb gefärbt, als vielmehr gelblich-blau, wie die von Fпмо aus Tlemcen erwähnten.

Fundorte: Aumale 11./7.; Dra el Mizane 18.7.; Bouira 16.7.; Blidah 13.66. (alle dort gefangenen Thiere prächtig nach der Umgebung gefärbt); Bir bou Rekbah 26./6. 01; Hammam el Lif 27.6. 01. 


\section{Pachytylus cinerascens (FABR.)}

Laghouat 24.6. 94; *Hammam el Lif 28.6. 01; ein grünes und ein braunes Weibchen; trotz der enorm weiten Verbreitung stets nur vereinzelt angetroffen.

\section{Oedaleus nigrofasciatus (DE GEER).}

Ihrer ungemein weiten Verbreitung (Europa, Asien, Afrika, Molukken, Neuholland) entsprechend ist die Art sehr anpassungsfähig und sehr variabel. Trotz der Verschiedenheit der algerisch-tunesischen Fundorte stiess ich auf keine irgendwie nennenswerthe Varietät, von den gewöhnlichen an ein und derselben Localität vorkommenden Differenzen in der Grösse und Farbe abgesehen. Nur in Laghouat scheint fast ausschliesslich die braune Farbe zu herrschen, auf den fast vegetationslosen Dünen um Gafsa dagegen leben braune und grüne Individuen gemischt. Larve und Imago sind mit einem vor dem Mesonotum unter der Metazone des Pronotums ausmünden- Pronotum von Oed. den Stinkapparat bewaffnet ${ }^{1}$ ); in den Nach- nigrofasciatus von oben. mittagsstunden zeigen die Thiere eine unge-

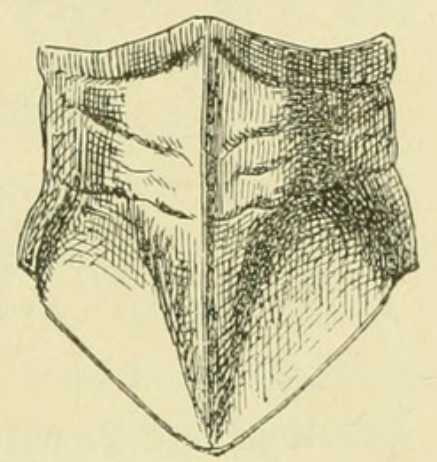
meine Vorsicht und Scheu, können kaum erjagt werden.

Fundorte: Dra el Mizane 18.7. 97; Aumale 10.7.; Djelfa 29./6.; Laghouat 20./6.; Hammam el Lif 28./6. 01; Sousse 12./6.; Gafsa 22./6.

\section{Oedaleus senegalensis (KRAUSS).}

Pachytylus senegalensis Krauss, Orthopteren von Senegal, in: SB. Akad. Wiss. Wien, V. 76,1877 , p. 56, tab. 1, fig. 9.

Oed. senegalensis Krauss, DE Sauss. Prodr., p. 117 u. Additam. ad Prodr., p. 42.

Ein Pärchen von Gafsa unterscheidet sich nur durch grössere Augen, kaum angedeutete Zeichnungen auf der Aussenseite und Oberkante der Hinterschenkel von der Originalbeschreibung. Beide Geschlechter sind kleiner als die Typen.

1) Näheres darüber in einem spätern Abschnitte. 


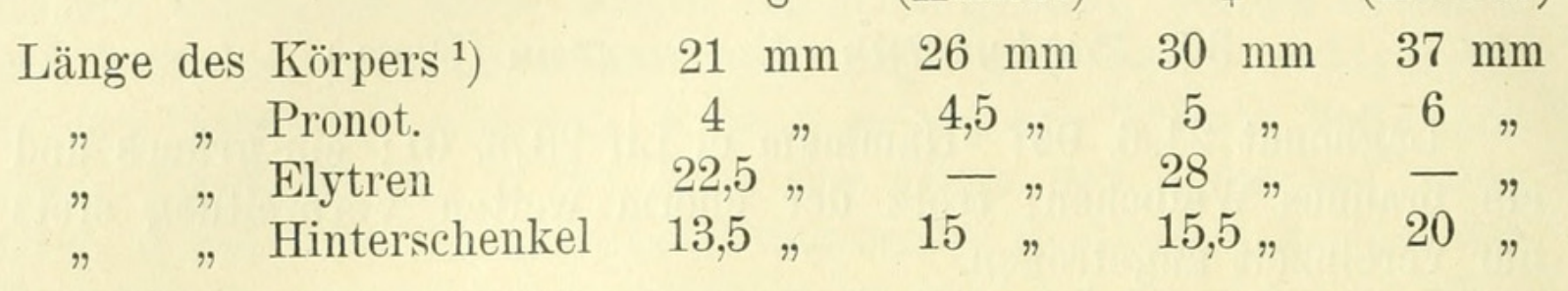

Die beiden einzigen gefundenen Exemplare lebten mitten unter der vorhergehenden Art in der Nähe der Bahnstation in Gafsa und fielen durch ihr weniger scheues und flüchtiges Wesen auf. Sie sind ebenfalls mit einem Stinkapparat versehen.

2

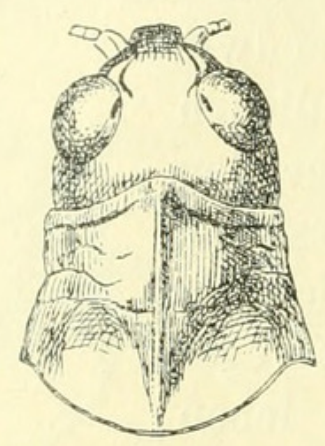

b

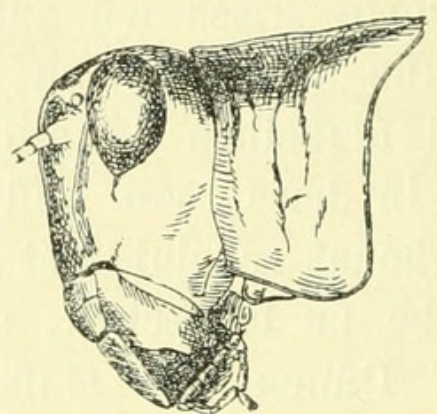

Kopf und Pronotum von Oed. senegalensis, a von oben, b von der Seite. $4: 1$.

Nach den Angaben von DE Saussure erstreckt sich Oe. senegalensis nicht nur über den grössern Theil von Mittel-, Süd- und Ost-Afrika, sondern kommt auch in Australien vor, da und dort mit kleinern Abweichungen in der Statur, Länge und Zeichnung der Elytren etc. Für unser Gebiet ist sie neu, der angegebene Fundort, bis jetzt der nördlichste bekannt gewordene, bildet einen weitern Beleg für die faunistischen Beziehungen zwischen dem Senegal und Nord-Afrika. ${ }^{2}$ )

\section{Acrotylus longipes (СHARP.).}

Im östlichen Mittelmeergebiet und in Kleinasien verbreitet, geht bis nach Abessynien und Zanzibar; ist in Algerien und Tunesien nicht gemein, kann aber stellenweise zahlreich auftreten. Die Flügel eines $q$ von Gafsa sind zart roth gefärbt, die eines andern von dort tragen einen leichten Hauch einer dunklen Binde.

1) Nach Alkoholexemplaren.

2) Auf den beistehenden Abbildungen sind die Zeichnungen auf Kopf und Pronotum weggelassen, um ein desto deutlicheres Bild der Verschiedenheit der 2 nord-afrikanischen Arten zu geben. 
Fundorte: Bir bou Rekbah 26.6. 01; Sousse 12./6.; Sfax 22.6. Graïba 19./6.; Gafsa 20./6.

\section{Acrotylus patruelis (Sturm.).}

Das Roth der Flügel ist bei den aus dem Süden (Aïn-Sefra, Laghouat) stammenden Individuen blasser als bei den Küstenbewohnern.

Fundorte: Blidah 13.6; Aumale 14.7; Laghouat 24.6.

\section{Egnatioides n. g.}

Von geringer Grösse, schlank; Kopf nach unten zurückweichend, Scheitel polygonal, vertieft, Ränder scharf erhaben, sich über die Augen fortsetzend; Scheitel und Occiput in der Mittellinie mehr oder weniger deutlich gekielt, schwach quergefältelt, seltener glatt. Stirnleiste zwischen den Antennen vorspringend, gerade, gefurcht, ihre erhabenen Ränder oberhalb der Ocelle annähernd parallel, unterhalb wenig divergirend; Stirngrübchen dreieckig, vertieft; Augen gross, kugelig, Antennen länger als Kopf mit Pronotum, schwach verdickt vor dem Ende. Pronotum wenig eingezogen mit eingedrückten Punkten, mit Mittelkiel, der zwischen den Querfurchen verschwindet, Hauptfurche in oder wenig vor der Mitte, Seitenkiele kaum angedeutet, Hinterrand halbkreisförmig, Unterrand der Seitenlappen schräg, geschwungen mit abgerundeten Ecken. Elytren denen von Egnatius und Leptocirtus sehr ähnlich. Flügel hyalin, im vordern Theil dunkler, im hintern bläuliches Gräder. Enddornen der Hintertibien etwas länger als die Hälfte des ersten Tarsalgliedes.

\section{Egnatioides striatus n. sp.}

(Taf. 17, Fig. 5-7.)

Syn, : ? Leptoscirtus aviculus Sauss, of, ? Finot, Faune de l'Algerie et de la Tunisie, p. 462.

Auf den beiden Reisen im Süden Algeriens und Tunesiens wurde sehr häufig eine kleine Oedipodide angetroffen, die auf den ersten Blick mit dem von mir früher bei Mecheria entdeckten Egnatius coerulans Krauss leicht zu verwechseln ist, sich aber durch gestrecktere Form des Körpers, glatteres, hinten gerundetes Pronotum, am Ende leicht zugespitzte Fühler u. s. w. unterscheidet. Dieselbe ist voll- 
kommen identisch mit dem von Finот mit Vorbehalt als Weibchen von Leptoscirtus aviculus ${ }^{1}$ ) Sauss. beschriebenen Thier von Biskra.

Zu Thrincus gehört die Art nicht, wie Fıмот ganz richtig hervorhebt, obgleich einige Kennzeichen damit übereinstimmen. Aus dem Folgenden ergiebt sich, dass sie auch nicht unter Leptoscirtus gestellt werden kann, trotz der weiten Fassung, welche dE Saussure der Diagnose dieser Gattung gab.

Das Frnot'sche Exemplar ist ausnahmsweise hell, zudem ziemlich frisch gehäutet. Nur 2 meiner Exemplare aus Laghouat sind noch heller gefärbt, beinahe licht strohgelb, alle andern aber sind licht bräunlich, sandfarben mit hellern Hinterschenkeln; Kopf, Thorax, Elytren und Unterseite der Hinterschenkel oft ganz milchweiss mit Ausnahme der dunklern Zeichnungen. Von diesen fallen zuerst die nie fehlenden, oft aber (wenn die Grundfarbe dunkel ist) weniger hervortretenden schwarz-dunkelbraunen Seitenstreifen auf, hinter dem Auge beginnend und an den Seiten des Pronotums sich fortsetzend (Fig. $5 \mathrm{a}, \mathrm{b}$ ). Weniger beständig ist der von Finot beschriebene, nach hinten sich verbreiternde Mittelstreifen auf dem Occiput, der meist durch eine hellere Längslinie in 2 getheilt ist. Mit diesen correspondiren oft 2, ab und $\mathrm{zu}$ stellenweise unterbrochene zartere Linien auf dem Pronotumrücken, welche auch nur durch stärkere Anhäufung dunkler Punkte angedeutet sein können und nach hinten ein wenig divergiren. Die Antenne ${ }^{2}$ ), mehr oder weniger deutlich geringelt, gegen das Ende einfarbig dunkelbraun, von oben nach unten leicht zusammengedrückt, hinter der Mitte etwas anschwellend, gegen das Ende sich verjüngend. Die Spitze wie abgebrochen, mit einer kleinen blassen Endfläche versehen. Die Grenzen der Endglieder kaum zu erkennen, die 5 letzten sehr kurz, scheinbar mit einander verwachsen. Länge der Antenne: $q$ 1/3 mehr als Kopf mit Pronotum, beim đo verhältnissmässig etwas länger.

Das Geäder der Elytren mit wenigen Ausnahmen von feinen schwarzen Punkten begleitet, zwischen den Adern zahlreiche kleine dunkle Fleckchen, an der Verbreiterung der Area mediastina eine tiefbraune Stelle.

Die Flügel sind im vordern Abschnitt schwarz geadert, hinten

1) In dankenswerther Weise sandte mir Herr Cap. Finot seinen Typus zur Vergleichung zu.

2) Die Beschreibung der Antenne basirt auf trockenen Exemplaren; in Alkohol ist sie mehr rundlich, die Anschwellung weniger deutlich, das Fehlen einer eigentlichen Spitze desto besser zu sehen. 
in beiden Geschlechtern bläulich angehaucht, die Aederchen etwas stärker als die Zwischenfelderchen.

Die mittlern Querfurchen des Pronotums etwas variabel, oft stark verwischt. Die Gestaltung der Brust finde ich mit Finot langgezogen, besonders das Mesosternum (Fig. 6), und hochgewölbt.

Der Rücken des Abdomens sehr deutlich gekielt. Die Subgenitalplatte des $q$ ist nicht mit 2 Längskielen versehen, sondern einfach gewölbt; ${ }^{1}$ ) auf der Mitte des geschweiften Hinterrandes in eine kurze Spitze ausgezogen.

Die von Fiмот erwähnte Querkante zwischen den Augen fehlt dem Scheitel oft gänzlich, die andern Erhabenheiten des Kopfes sind beständiger, vor Allem der den Oberrand der Augen begleitende Seitenkiel des Scheitels und die davon radiär gegen die Mittellinie abgehenden Fältchen.

$\begin{array}{ccccc}\text { Long. corp. } & 11,5-12,5 \mathrm{~mm} & 14,5-16,5 \mathrm{~mm} \\ , \quad \text { pron. } & 1,9-2,1 \quad " & 2,5-3 & \\ " & \text { elytr. } & 10-11 \quad " & 13-15 \quad "\end{array}$

Die Cerci der ठठ์ finde ich stärker behaart als die der $+\circ$, sonst aber gleich (Fig. 7).

Ist es auch nicht gerade leicht, die Beschreibung Finot's und die hier gegebenen Ergänzungen dazu mit der etwas kurz gehaltenen DE SAussure's über die Gattung Leptoscirtus zu vergleichen, so kann doch mit ziemlicher Bestimmtheit behauptet werden, dass keine der 3 Arten dieser Gattung mit unserm Thier übereinstimmt. Am ehesten könnte es noch nach Finot's Vorgang mit $L$. aviculus Sauss. vereinigt werden. Davon trennt sie aber die stark nach unten zurückfliehende Stirne, welche zwischen den Antennen auffallend weit vorspringt, deren Seitenkiele scharf ausgeprägt unterhalb der Mittelocelle sich schwach divergirend fortsetzen; von der nicht zu übersehenden Plastik des Scheitels und der obern Augenränder erwähnt DE Saussure nichts, betont dagegen, dass der Unterrand der Pronotums gerade, die Enddornen der Hintertibien nur ein wenig kürzer als das 1. Tarsalglied seien. Da weiterhịn die wesentlichsten Eigenschaften der Gattung, also nach DE SAussure: côte faciale très

1) Am trocknen Exemplare sind wohl ab und zu solche zu sehen; sie entstehen aber nur dadurch, dass der weichere Mitteltheil der Platte einsinkt, auch beim Männchen. 
comprimé, presque lamellaire, ... et qui, au dessous de l'ocelle, s'efface entièrement, ferner die langen Enddornen der Hintertibien fehlen, bleibt nichts anderes übrig, als die Art von Leptoscirtus zu trennen und eine besondere Gattung dafür aufzustellen. Meiner Ansicht nach steht diese Egnatius am nächsten, erinnert aber auch an Acrotylus.

Fundorte: Djelfa 28.6. 97 häufig, Bou Saâda 7.7., Laghouat 22.6., Bir bou Rekbah 26.|6. 01, Sousse 12.6., Graïba 19.6., Gafsa 22. 6., Gabès 17.6.

Tritt fast stets zusammen mit Stauronotus genei auf. Vermuthlich ist die zweite, von Frey-Gessner ${ }^{1}$ ) mit einem Fragezeichen versehene Egnatius-Art mit der hier beschriebenen identisch und käme also auch in Aïn Sefra (Oran) vor. Auch die beiden Bronner'schen Exemplare von dort (Fплот p. 463) rechne ich nach Autopsie hierher. Daraus ergiebt sich die Verbreitung vom Süden Orans über den ganzen Süden Algeriens und Tunesiens, vorwiegend im Gebiet der Wüste. Bei Bir bou Rekbah liegt der nördlichste Punkt des Vorkommens.

Helioscirtus de SAussure 1884.

Diese Gattung, zunächst auf eine aus Turkestan und Persien stammende Art (H. moseri DE SAuss.) gegründet, erhielt später ${ }^{2}$ ) noch einigen Zuwachs, der aber eine Modification der Gattungsdiagnose mit sich brachte, derart, dass nun die Verdickung der alternirenden Axillaradern eigentlich den ganzen Unterschied von Sphingonotus bildet. Finot lässt die Frage offen, ob es sich nicht nur um eine Untergattung davon handle. Die eine der 2 neu hinzugekommenen Arten, H. finotianus DE Sauss., sticht von den andern durch das Geäder des Flügels ab; die zwischen den Axillaradern stehenden Queräderchen sind weniger zahlreich und dick, der ganze Flügel ist schmäler, gestreckter als bei $H$. capsitanus Bonnet und trägt eine mehr oder weniger deutliche dunkle Binde. Alle diese Merkmale aber kommen der Gattung Sphingonotus zu, auf welche die übrigen Eigenschaften ohnedies hinweisen. Das einzige Characteristicum, die Verdickung der Axillaradern, verliert nach Fergleichung eines umfangreichen Materials von andern Sphingonotus-Arten sehr an Bedeutung. Zunächst lässt sich feststellen, dass sie in einigermaassen

1) In: Mitth. Schweiz. entomol. Ges., V. 9, Hft. 3, 1894, p. 103-109.

2) Additamenta ad Prodr., Oedipodiorum, 1888, p. 74. 
auffallendem Grade nur bei den $\delta \delta$ vorkommt, hier aber, noch mehr bei den $q+$, sehr veränderlich ist, dass sie ferner, ebenfalls in wechselnder Ausbildung, auch bei Sphingonotus mecheriae Krauss, balteatus SERv. u. A. anzutreffen ist. Diese Dickendifferenzen bringen es mit sich, dass manche Individuen der angeführten Arten stärkere Axillaradern haben als $H$. finotianus. Trennt man ihn davon, so gewinnt die Gattung wesentlich an Charakter und kann etwa durch folgende Kennzeichen von Sphingonotus unterschieden werden:

Körper gedrungener als bei Sphingonotus; Elytren breit, gegen das abgerundete Ende sich kaum verschmälernd, unregelmässig und verschwommen gefleckt, die allgemein auftretenden Querbinden kaum hervortretend, Vena intercalaris sich rasch den Radialnerven nähernd, auf der Oberseite mit kleinen Zähnchen ${ }^{1}$ ) bei ơ und $q$; Flügel, an die von Bryodema erinnernd, breit; ihr Hauptgeäder, besonders die Axillaradern, gewöhnlich stark verdickt, am Ende zugespitzt, die Zwischenäderchen im hintern Flügelabschnitt stark

1) Es handelt sich hier um einen Zirpapparat, homolog der Schrillader der Locustiden, analog den Zäpfchenreihen auf der Innenseite der Schenkel vieler Acridier. Während dort die Zäpfchen über die scharfe Kante einer Flügelader gestrichen werden, streicht hier (wohl die Oberkante oder) die obere Innenkante des Schenkels über die Zähnchen. Das Princip des Musikinstruments ist somit dasselbe. Der Ton lässt sich künstlich mit einem Messer erzeugen, dessen Schneide leicht über die Ader hingeführt wird. Die Sphingonotus-Arten einschliesslich des $H$. finotianus entbehren dieser Einrichtung oder besitzen nur zum Zirpen ungenügende Spuren davon. Auch andere Adern von Acridiern tragen oberseits regelmässig quer gestellte Erhabenheiten, an Stellen, wo sie nie zum Zirpen dienen können. Aus diesen entwickeln sich offenbar die sogenannten Schrillplatten, als weitere Stadien einer wohl ursprünglich zufälligen oder für andere Zwecke bestimmten Structur, aus diesen sodann die Zähnchen, beide auf besonders stark erhabenen Stellen des Vorderflügels oder des Pronotums*) so angeordnet, dass sie von einer scharfkantigen Leiste, sei es des andern Vorderflügels oder des Hinterschenkels, bestrichen werden können. In unserm Falle liegt, ähnlich wie Epacromia strepens, die gezähnelte Intercalarader höher über der Oberfläche der Elytren, als die andern Venen. Die sogenannten Zäpfchen der Innenseite der Hinterschenkel vieler Acridier entstehen bekanntlich durch Umbildung von Haaren.

*) Bei Tettix bipunctata. Vgl. Petrunkewitsch, A., u. Georges voN GUaIta, Ueber den geschlechtlichen Dimorphismus bei den Tonapparaten der Orthopteren, in: Zool. Jahrb., V. 14, Syst., Hft. 4, 1901, p. 6. 
hervortretend, eng gestellt, besonders gegen die Wurzel zu, parallel oder subparallel dem Aussenrand. Hintertibien gelb oder roth, mit kurzen Enddornen, die äussern wenig kürzer als die innern.

Am meisten Gewicht ist auf die Proportionen und die Aderung der Flügel zu legen. Die Länge verhält sich bei den 2 im Folgenden aufgeführten Arten zur grössten Breite

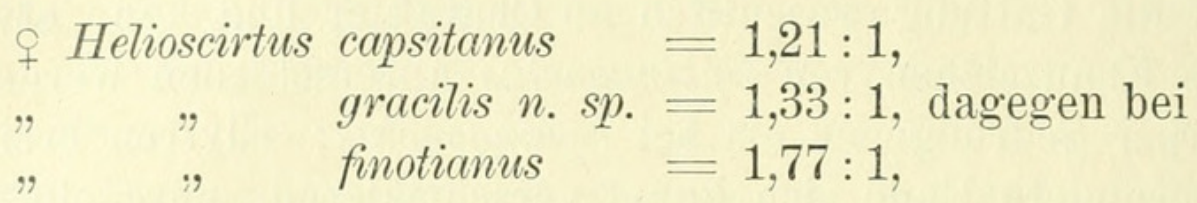

ein Verhältniss, das auffallend absticht und vortrefflich sowohl im Einzelnen als im Durchschnitt, den bei 10 Arten der Gattung Sphingonotus gefundenen Werten entspricht. Zum Vergleich setze ich diese hierher:

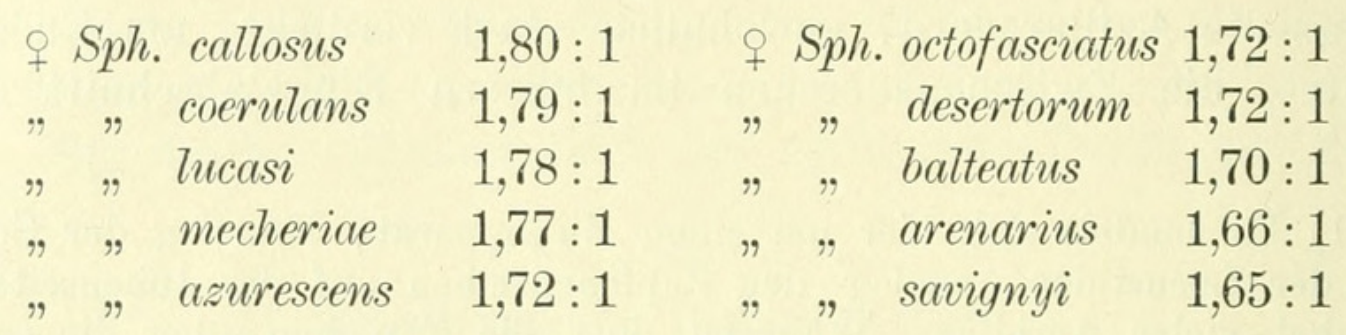

Im Mittel also 1,731:1. Die Flügelmembran von Helioscirtus ist mehr glasig, die von Sphingonotus häutig, ebenso bei $H$. finotianus, bei dem auch die Zwischenäderchen schief, nicht rechtwinklig, von den Axillaradern abgehen, nicht besonders hervortreten, gegen die Flügelwurzel zu spärlicher werden und weiter gestellt sind. Auf Grund dieser vollkommenen Uebereinstimmung des Flügelbaues wird $H$. finotianus unter die folgende Gattung verwiesen.

\section{Helioscirtus capsitanus (BONNET).}

(Taf. 18, Fig. 8 a-e und Textfig.)

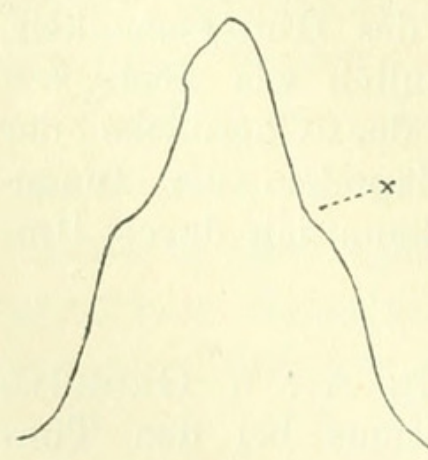

Schwirrlinie von H. capsitanus.

Ausgezeichnet durch eine ganz enorme Anpassungsfähigkeit an die Farbe des Bodens (vgl. Th. II) und durch sein Schnarrvermögen. Weibchen wie Männchen pflegen sich in den Mittagsstunden, d. h. am lebhaftesten etwa von 9-4, in kurzen Zwischenräumen etwa $1^{1 / 2}$ bis $2 \mathrm{~m}$ in einigen Windungen schwirrend über den Boden zu erheben und sich überschlagend (bei x der beistehenden Fig.) wieder fallen zu lassen. Dabei 
erzeugen sie ein so lautes Geräusch, zumal wenn mehrere beisammen sind, dass jedes Gespräch verstummen muss. Sie übertönen selbst das Brausen des heftigsten Orkans. Nie hätte ich es für möglich gehalten, dass ein so kleines Insect einen solchen Lärm erzeugen kann, der am ehesten dem rasselnden Geklapper des unter dem Namen „Rätsche“ bekannten Instruments vergleichbar ist. Erzeugt wird der Ton zweifellos bei der Bewegung der Hinterflügel, vermuthlich aber nur in dem Momente, wo derselbe nicht vollkommen entfaltet ist. Ein Theil des kurzen Auffluges verläuft ebenso geräuschlos wie kurze Pausen während längerer beim Jagen zu beobachtendender Horizontalflüge. Das am Kopf ergriffene Thier schnarrt mit ganz wenig abstehenden Flügeln; dass diese dabei an die Hinterbeine anschlagen, erscheint mir unwahrscheinlich; sicherlich kommen die verdickten Axillaradern nicht damit in Berührung, da sie bei der fächerartigen Faltung die Oberkanten der senkrecht gestellten Falten bilden. Viel eher ist es denkbar, dass die nach unten vorspringenden Längsadern der Elytren über diese Adern wegstreichen und so die Falten zusammenklatschen lassen oder dass die Flügel überhaupt bei bestimmten Acten der Flugbewegung gegen die Unterseite der Elytren vibriren. Besondere auf die Tonerzeugung hinweisende Eigenschaften sind an derselben aber nicht zu bemerken.

Ein Zusammenhang zwischen der Structur der Flügel und der Stärke des Rasselns ist unverkennbar. In der schönen Bryodema tuberculata FABR. besitzt die europäische Fauna ein Gegenstück zu Helioscirtus nicht nur im Habitus und in den Lebensgewohnheiten, sondern ganz speciell auch in Bezug auf die Form und den Bau des Flügels und die Erzeugung weithin vernehmbarer Schnarr- oder Klappertöne. ${ }^{1}$ ) Hier ist ebenfalls der Flügel stark verbreitert, fast gerundet, glasig glänzend, die Axillaradern verdickt, die Zwischenäderchen zahlreich, eng gestellt u. s. w., kurz genau wie bei Helioscirtus beschaffen, so dass man sich versucht fühlt, auf diese Uebereinstimmung: hin die Gattung wieder nach Bonnet's Vorgang zu Bryodema zu stellen oder sie als Zwischenglied zwischen Bryodema und Sphingonotus anzusprechen, worauf SAussure (Additam. ad. Prodr., p. 76) anspielt, allerdings nur wegen der gekielten Unterseite der mittlern Tibien.

Fundorte: Laghouat 22./6. 97. Ist offenbar ein echtes Wüstenthier, kommt auch bei Aïn Sefra (Finot) und am Col de Sfa (Brunner)

1) cf. KRauss, H., Beitrag zur Kenntniss der alpinen Orthopterenfauna, in: Wien. entomol. Ztg., V. 5, Hft. 9, 20. Nov. 1886, p. 321. 
ferner in Tunesien zwischen Sfax und Gafsa vor, stellenweise wie bei Laghouat häufig; liebt wie Bryodema und die folgende Art steriles, steinig-sandiges Gelände.

\section{Helioscirtus gracilis n. sp.}

Der vorigen Art sehr ähnlich, kleiner, gelblich-grau, schlank. Unterscheidet sich von $H$. capsitanus durch zierlichern Kopf, dessen Hinterhaupt wenig gewölbt, dessen Scheitel zwischen den Augen schmäler ist; Pronotum schwächer eingezogen, Hauptfurche vor dem ersten Drittel, der dahinter liegende Metazone-Abschnitt des Discus nicht mit Seitenkanten, sondern gerundet in die Seitenlappen übergehend, Mittelkiel zwischen den Furchen verwischt, auch sonst nur schwach angedeutet. Intercalar- und vordere Ulnarader auffallend stark gebogen (s. Abbbildung). Flügel viel schlanker, besonders

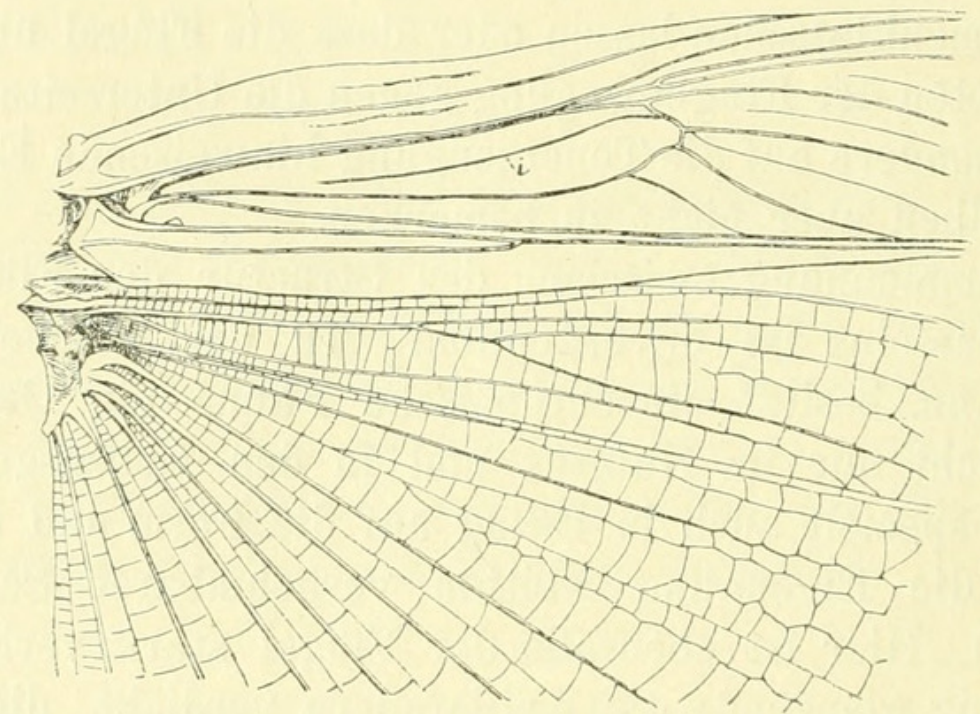

Basiliare Hälfte des Vorder- und Hinterflügels von H. gracilis. $i$ Intercalarader.

gegen die Spitze zu, Axillaradern beim $q$ nicht verdickt. Zwischenäderchen nur wenig hervortretend, sonst wie vorher. Flügel gelblich, blass, hyalin.

$$
\begin{aligned}
& \text { Long. Corp. } q 15,5 \mathrm{~mm} \\
& \text { "Pronot. " } 5 \text {, } \\
& " \text { Elytr. " } " 2,5 \text { " } \\
& \text { " Femor. post. "11,5 " }
\end{aligned}
$$


Fundort: Gafsa 21./6. 01, nur 1 ․

Das Rasseln bezw. Schnarren ist weniger stark als bei H. cap sitanus, immerhin noch recht vernehmlich. In der Ruhe zirpte das einzige beobachtete Weibchen schwach und etwas rauh; seine Färbung harmonirte vollkommen mit der Bodens seiner Umgebung:

\section{Sphingonotus FABR.}

Die Unterscheidung der Sphingonotus-Arten mit hyaliner oder blaugetönter Flügelbasis bezeichnet Fгмот als undankbar und schwierig und glaubt, dass die verschiedenen Arten eigentlich nur Formen oder Varietäten von Sph. coerulans L. seien, mit dieser Art und Sph. balteatus als den extremsten Gliedern dieser Formenreihe. Auch Sph. sefrae, selbst die Gattung Helioscirtus (in der frühern Fassung), könne darin einbezogen werden.

Nach Durchmusterung umfangreicher Serien von den nord-afrikanischen Arten kann ich mich dieser Ansicht nicht unbedingt anschliessen. Wohl wirkt der Einfluss der Umgebung in mehreren Richtungen bald nivellirend, bald entgegengesetzt, bei allen individuellen oder localen Schwankungen der Artmerkmale wird aber eine bestimmte Grenze nie überschritten, die Trennung von den nächst verwandten Arten nie verwischt. Eine ganze Reihe für das Wohl oder Wehe des Individuums oder für die Erhaltung der Art vielleicht vollkommen indifferenter Eigenschaften bleiben als eiserner Bestand erhalten, um welche die übrigen, wechselvoll, veränderlich, sich gruppiren. So vermag das geübte Auge leicht allein der Zeichnung der Elytren als Wegweiser zur Bestimmung der Arten zu folgen. Trotz aller Variabilität bewahrt sie innerhalb der Art eine ganz bestimmte Anordnung, Stärke und Begrenzung, d. h. sie kann fast bis zur Unsichtbarkeit vergehen oder in der allgemeinen Färbung scheinbar aufgehen, allein die geringsten noch nachzuweisenden Spuren können nur an dem einmal festgelegten Platze auftreten und lassen noch etwaige Nuancirungen und Abgrenzungslinien erkennen. Aehnlich steht es mit der Form und der Sculptur von Kopf und Pronotum. Die Unterschiede zwischen zwei Arten sind oft minutiös, müssen aber gelten, sobald sie regelmässig vorkommen, selbst dann, wenn sie schwieriger zu beschreiben als zu sehen sein sollten.

Selbstverständlich wird damit keineswegs das Vorkommen von Varietäten in Abrede gestellt noch der Vereinigung besonders schwierig zu unterscheidender Arten entgegengetreten. Besonders revisionsbedürftig scheint mir für das Gebiet die Gruppe: Sph. 
azurescens, callosus, scabriusculus und arenarius zu sein, ganz abgesehen von den vielen nicht immer ganz mit Recht als Varietäten bezeichneten Formen aus andern Bezirken, welche dE Saussure (Addit. Prodr.) als entstehende Arten (in Folge localer Rassebildung) anführt.

\section{Sphingonotus finotianus (SAUSS.).}

Helioscirtus finotianus SAUss., in: Le Naturaliste, 1885, p. 28, ठ. Helioscirtus finotianus SAuss., in: Additam. ad. Prodr. Oedipod., 1888, p. 75, ठे.

Die Gründe der Versetzung dieser Art in die Gattung Sphingonotus wurden früher angegeben. Mehrere Stücke von Bou-Saâda und Gafsa zeigen keine Spur der gewöhnlich angedeuteten dunkeln Binde auf den Hinterfïgeln. Das zarte, auf den Axillaradern verstärkte Blau ist an einzelnen Exemplaren von Gafsa durch Roth ersetzt. Die Form ohne Binden ist leicht mit Sph. coerulans zu verwechseln, besonders wenn die Axillaradern nur schwach verdickt sind, aber durch die Zeichnung der Elytren zuverlässig davon zu unterscheiden. Das basale Drittel derselben ist nämlich von dunklerer (meist homogener) Grundfärbung als das übrige, eine schräg verlaufende Linie, nach aussen scharf abgegrenzt nach innen kurz verwaschen, schliesst diesen Theil ab. Diese Grenze verläuft continuirlich, mehr oder weniger gerade, seltener unregelmässig gezackt. Auch die zweite Binde, etwas jenseits der Mitte, ist häufig scharf ausgeprägt, nie in zahlreiche Einzelfleckchen aufgelöst, wie bei $S p h$. coerulans.

Fundorte: Blidah 3./6. 97; Bouira 6./7.; Bou-Saâda 5.7.; Laghouat 20.6.; Hammam el Lif 28.6. 01; Bir bou Rekbah 26.6.; Gafsa 22./6. Finот kennt die Art nur aus West-Algerien, hauptsächlich Oran, wo ich sie auch früher bei Mecheria fand. Wie man sieht, bewohnt sie das ganze Gebiet und reicht von der Küste bis tief ins Innere.

\section{Sphingonotus mecheriae (KRauss).}

(Taf. 17, Fig. 9a, b-10.)

Sphingonotus sp., Savigny, Descript. de l'Egypte; tab. 7, fig. 10.

Sphingonotus coerulans L. var. mecheriae KRSs., in: Jahresh. Ver. vaterl.

Naturk. Württemberg, 1893, p. XCV; Zool. Jahrb., V. 9, Syst., 1896, p. 534, fig. 4.

Auch diese Art steht Sph. coerulans sehr nahe. Nachdem ich weiteres reiches Material davon gesammelt habe, lässt sich bestimmt 
angeben, dass es sich nicht um eine Varietät, sondern um eine wohl ausgeprägte Species handelt. $\mathrm{Zu}$ den von Krauss veröffentlichten Diagnosen sind noch weitere Merkmale hinzuzufügen.

Kopfgipfel nur wenig über den Vorderrand der Augen vorstehend. Pronotum stark eingezogen, Hauptquerfurche nur wenig vor der Mitte (Fig. 9a, b), Seitenlappen so hoch wie breit, Unterrand schräg, leicht geschwungen, Vorderecke ausgezogen, fast spitzig, Hinterecke scharf, Hinterrand der Metazone einen schwach, beim $\delta$ stärker abgerundeten, stumpfen Winkel bildend. Episternum (Fig. 9 b e dreieckig, (bei coerulans gerundet, Fig. $11 \mathrm{~b} e$ ). Elytren (Fig. 10) schmal mit 2 dunkeln Binden, die stets vor den Radialadern dunkler als dahinter, unregelmässig begrenzt, oft unterbrochen sind; jenseits der zweiten Binde einzelne dunklere Felderchen. Flügel zart blau angehaucht mit dunklerm Geäder; Hauptadern oft schwarz. Innenseite der Hinterschenkel mit 3 schwarzen Flecken, Hintertibien gelb.

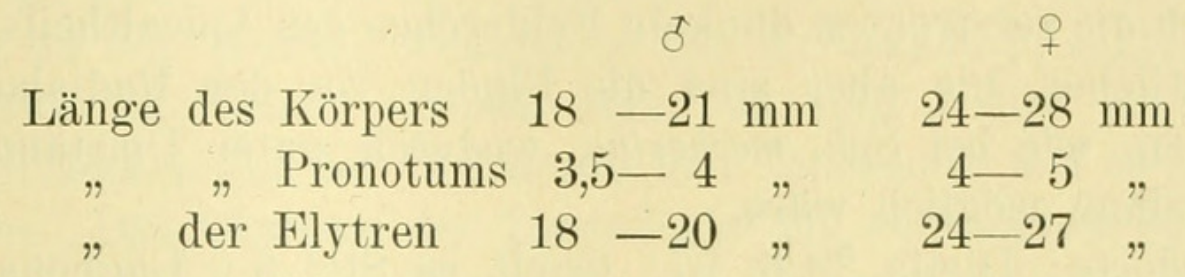

Während bei Sph. coerulans Kopf und Thorax dicht aber fein behaart sind, ist dies bei Sph. mecheriae nur äusserst spärlich der Fall. Bei gleicher Länge der Elytren sind die der neuen Art schmäler, das ganze Geäder gestreckter. Die Unterschiede in der Form des Kopfes, Pronotums und des Episternums sind aus den Abbildungen ohne Weiteres ersichtlich. Ab und zu tritt auf dem Pronotum eine Xförmige helle, dunkel begrenzte Zeichnung auf, deren vordere Zweige bis zur Hauptquerfurche verschmolzen sein können, von dort an aber rasch divergiren.

An der auffallenden Gestaltung des Pronotums mit seinen Erhabenheiten und dem sonst nicht wiederkehrenden Verhältniss zwischen den durch die Hauptfurche geschiedenen Abschnitten ist auch die Larve leicht zu erkennen.

Fundorte: (Mecheria, Khreider 92/94); Laghouat (häufig) 20./6. 97; Tunis 10./6. 01; Gabès 15.|6.; Gafsa 20./6.; an vielen Orten (AïnSefra, Laghouat, Tunis, Gafsa, Gabès) gemeinsam mit der folgenden Art. 


\title{
40. Sphingonotus coerulans (L.).
}

\author{
(Taf. 17, Fig. 10 a,b.)
}

Von den verschiedenen, durch DE SAussure veröffentlichten Varietäten (Additam. ad. Prodrom. Oedipod. p. 79-80) wurde eine der var. vitrea nahestehende, aber grosse Form fast ebenso häufig wie die Stammform angetroffen, oftmals beide neben einander. Sie ist nicht nur durch die, nahezu oder ganz, glashellen Flügel, sondern auch durch einen, besonders beim ơ, deutlichen, schlankern Habitus ausgezeichnet. Die Axillar- und Zwischenadern sind in einer den halben Flügel einnehmenden Randzone dunkel. Häufig kommt auf dem Pronotum die vorhin erwähnte, auch sonst anzutreffende X förmige Zeichnung vor. In demselben Maasse, wie bei meinen Exemplaren das Blau der Flügel schwindet und dafür das Geäder durch seine kräftige Färbung sich hervorhebt, werden auf den Elytren die bekannten Zeichnungen, also ausser den üblichen beiden Binden auch noch die zerstreuten dunkeln Felderchen des Apicaltheils, stärker und deutlicher, nie aber sind die Binden vor den Radialadern am dunkelsten, wie bei Sph. mecheriae, wodurch unter Umständen eine Verwechslung möglich wäre.

Fundorte: Djelfa 29.6. 97; Guelt es Stel 6.; Laghouat 20./6.; Bou Saâda 29./6; Sousse 12.6. 01; Gafsa 20.6.; Gabès 15.6.

\section{Sphingonotus desertorum n. sp. $\left.{ }^{1}\right)$}

(Taf. 17, Fig. 12a,b-13.)

Klein, gelb- bis graubraun. Scheitel an den Seiten deutlich, in der Mitte kaum merklich gekielt. Kopfgipfel vorstehend, Stirn fast senkrecht. Augen weit aus einander stehend, gross, beim ठ stärker hervortretend als beim $q$; zwischen denselben auf dem Hinterhaupt einige schwache Erhebungen. Stirngrübchen klein, undeutlich. Stirn-

1) In seiner jüngsten Arbeit hat Krauss die Art ebenfalls als neu beschrieben und nach mir benannt, was mir um so überraschender war, als er bei wiederholten Besuchen sich überzeugt hatte, dass meine Sphingonoten schon im vergangenen Herbst vollständig bearbeitet waren und sich fragliche Art darunter befand. Nachdem er diese Anfangs dieses Jahres abermals besichtigt, theilte er mir bei seiner letzten Anwesenheit (18./1. 02) mit, dass auch unter seinem Material das Thier sich befinde und von ihm als Sph. deserticola bezeichnet worden sei. Dabei erfuhr er, dass mein Manuscript mit Zeichnungen zur Absendung bereit liege. Dasselbe war am 25.11. in Giessen; nach brieflicher Mittheilung vom 8./5. 02 sandte Krauss das seinige am 1./2. 02 nach Wien ab. 
leiste mit deutlichen Seitenkielen, über und unterhalb der Ocelle verschmälert. Pronotum rauh, Mittelkiel vor der ersten Querfurche stark erhaben, zwischen dieser und der Hauptquerfurche obliterirt, auf der Metazone wieder deutlich; in der Mitte vor der Hauptquerfurche zwei kleine napfförmige Erhabenheiten, deren Vorderrand häufig niedergedrückt, deren hoher Hinterrand gewöhnlich rein weiss ist. Prozone: Metazone $=2: 3$, Winkel des Hinterrandes deutlich abgerundet, besonders beim $\delta$. Elytren lang schmal, gegen das Ende sich wenig verjüngend und leicht gebogen; Anfangs undurchsichtig, nach aussen hyaliner, mit 2 mehr oder weniger vollständigen schwarzbraunen Querbinden, deren dunkelster Theil, oft nur in einem Fleckchen bestehend, vor den Radialadern liegt, und unregelmässigen schwarzbraunen Felderchen im ersten, deutlicher im letzten Drittel. Hintere Radialader vor ihrer Gabelung nicht besonders weit von der mittleren entfernt. Intercalarader gerade, näher der hintern Radial- als der Ulnarader. Axillarader beim of frei, beim $q$ nicht. ${ }^{1}$ ) Flügel hyalin, an der Wurzel, wenigstens die Axillaradern, zartblau, selten mit ganz schwachen Spuren einer dunkeln Binde in der Mitte. Hinterschenkel auf der Oberkante und Innenseite mit 2-3 dunkeln Flecken. Das Centrum der Innenfläche oft verwaschen schwärzlich; Hintertibien Anfangs gelblich hell, mit einem schwarzen Flecken auf der Innenseite unter dem Gelenkknopf, etwa von der Mitte an schwach blau, dicht behaart; Enddornen kurz, die innern wenig länger als die äussern.

\begin{tabular}{|c|c|c|c|}
\hline & & & \\
\hline & es Köl & $13-14 \mathrm{~mm}$ & $21-22 \mathrm{~mm}$ \\
\hline & $\begin{array}{l}\text { " Pronotums } \\
\text { der Elytren }\end{array}$ & ${ }^{3}{ }^{13,5-14,5}$ & 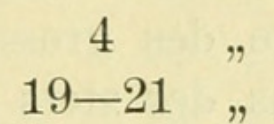 \\
\hline
\end{tabular}

Gewissermaassen eine Diminutivform von Sph. mecheriae ist die Art vielleicht mit $S p h$. niloticus SAuss. nahe verwandt ${ }^{2}$ ), aber grösser und weiterhin durch den hohen Kiel auf dem Vordertheile des Pronotums, durch die rauhe Metazone, durch den Mangel der Flecken an

1) Unter je 7 Exemplaren beider Geschlechter war eine Ausnahme davon $\mathrm{zu}$ beobachten.

2) Nach Finot ist das $q$ dieser Art noch unbekannt. Saussure, in: Mitth. Schweiz. entomol. Ges., V. 8, 1893, p. 96 u. Krauss, in: Verh. zool.-bot. Ges. Wien, Jg. 1890 , p. 265, weisen aber darauf hin, dass die einzige bisher bestehende Abbildung bei SAVIGNY, tab. 7, fig. 2 ein $q$ darstellt. 
den Seitenlappen, den Verlauf der der hintern Radialader genäherten Intercalarader zu unterscheiden.

An einigen Exemplaren sind die Erhabenheiten von Kopf, Pronotum, einzelne Aederchen der Elytren milchweiss. Auf dem Grundton von Kopf (mit Mundwerkzeugen), Pronotum und an den Seiten des Meso- und Metanotums sind grössere oder kleinere dunkelbraune Punkte unregelmässig vertheilt.

Fundorte: Gabès 15./6. 01; Gafsa 22.6. Als ausgesprochene Wüstenform wahrscheinlich weit verbreitet.

\section{Sphingonotus a*urescens (RАмв.).}

Nicht häufig gefunden, in Tunesien gar nicht, obwohl die Art über das ganze Gebiet bis in den Süden verbreitet ist.

Blidah 13.6. 97.

\section{Sphingonotus azurescens var. lutea KraUss.}

Sphingonotus sefrae SaUss. (i. 1.).

Sphingonotus sefrae Sauss., Finot, in: Ann. Soc. entomol. France, 1895, p. 476 .

Sphingonotus azurescens var. lutea KRAuss, in: Jahresh. Ver. vaterl. Naturk.

Württemberg, 1893, u. Zool. Jahrb., V. 9 , Syst., 1896, p. 535, tab. 7 , fig. 5 .

Obwohl Krauss die Abstammung dieser schönen, durch die Gelbfärbung der Flügel vereinzelt in der Gattung stehenden Varietät von Sph. azurescens klar ausgesprochen hat, führt sie Finot doch als Art auf und lässt sie dem Sph. scabriusculus näher verwandt sein, ohne des grossen Unterschiedes zu gedenken, der sich schon allein aus der stets rauhen Oberfläche von Kopf und Pronotum bei letzterer Art ergiebt.

$\mathrm{Zu}$ den frühern Fundorten im Süden Orans kommt als erster mehr nördlich und östlich gelegener Aumale bei Algier 9./7. 97 hinzu. Das dort angetroffene o hat nur leicht, aber mehr röthlich-gelb gefärbte Flügel, stimmt aber sonst ganz mit meinen Stücken aus Oran überein.

\section{Sphingonotus Tucasii (SAUSS.).}

Sphingonotus scabriusculus (eigentl. scabriculus) STÅL. var. lucasii SAUSS., in: Addit. Prodr., p. 83.

Sphingonotus scabriusculus StÅL., Finot, in: Ann. Soc. entomol. France, 1895, p. 474. 
Nachträglich bot sich mir die Möglichkeit, das von Krauss ${ }^{1}$ ) beschriebene typische Männchen von Sph.scabriculus STÅ̃. mit der von DE Saussure als var. Tucasii unterschiedenen nordafrikanischen Form zu vergleichen, wobei es sich zeigte, dass beide nahe verwandte aber selbständige Arten sind. Auf die ausführliche Beschreibung Finot's von Sph. Tucasii verweisend, bemerke ich, dass Sph. scabriculus stets viel grösser ist, breitere Elytren mit stark ausgeprägten, geradlinig und parallel begrenzten Binden, in der ersten Hälfte hat, dass die sehr breite, dunkle Binde der Flügel gegen den Vorderrand sich kaum verschmälert, ihr äusserer Umriss keinen distal vorspringenden Winkel auf der Höhe des ersten Axillarstrahles bildet. Die Augen des ơ weniger prominent; die Prozone des Pronotums relativ kürzer, mit schwächern Erhabenheiten besetzt, die Querfurchen schwächer ausgebildet, die männlichen Cerci, relativ kurz, erreichen das Ende der Subgenitalplatte nicht (wohl aber bei lucasii). Hierzu kommen noch regelmässige Verschiedenheiten der Hinterbeine. Bei Sph. scabriculus ist die Innenseite der Schenkel und die untere Rinne schwarz, die Tibia, mit Ausnahme des ersten Viertels, blau; bei Sph. Tucasii trägt die Innenseite der Schenkel 2 nicht auf die Rinne übergreifende dunkle Flecken, die Tibia ist gelblich, hat ganz selten einen zarten Anflug von blau.

Sph. Tucasii

Länge

des Körpers

„Pronotums

der Elytren

„ Hinterschenkel

$\begin{array}{cccc}13-14 & \mathrm{~mm} & 18-21 & \mathrm{~mm} \\ 2,5-3 & \prime & 3,8-4,2 & \\ 14,5-16 & \prime & 20-23 & " \\ 7,5-8 & " & 10 & "\end{array}$

Sph. scabriculus

Von den 28 untersuchten Exemplaren von Sph. Tucasii (darunter 11 ठठ), bot kein einziges Merkmal eine Uebergangsform zu Sph. scabriculus dar.

Fundorte: Aumale 7. 97; Dra el Mizane (häufig) 19./7.; Bouira 7.; Djelfa 3./7.; Sidi Maklouff 28.6. (ans Licht angeflogen); Laghouat 24./6.; Sfax 23.6. 01; Graïba 19.6.; Gafsa 20./6. Den Flügeln der Exemplare von Graïba fehlt die blaue Basis vollkommen.

1) Krauss, H., Beitrag zur Kenntniss der Orthopteren DeutschSüdwestafrikas, in: Verh. zool.-bot. Ges. Wien 1901, p. 286. 


\section{Sphingonotus diadematus n. sp.}

(Taf. 17, Fig. $13 \mathrm{a}-$ b, Taf. 18, Fig. 12.)

Mittelgross, gedrungen, gelb- bis schiefergrau, ziemlich glatt. Kopf breit, Augen am Scheitel weit getrennt. Stirne senkrecht, Scheitel flach abfallend, wenig über die Augen vorspringend, etwa 5 eckig, mit leicht erhabenen Seitenkielen und einem schwachen, nach hinten sich verflachenden Mittelkiel. Stirngrübchen deutlich gross 3 eckig, aber kaum vertieft. Hinterhaupt steil mit radiären, vom hintern Augenrand ausgehenden Fältchen. Stirnleiste breit, flach mit deutlichen, am Kopfgipfel und unterhalb der Ocelle genäherten Seitenkielen. Ueber die Stirne zieht sich von Auge zu Auge ein schwarzes Band, dessen Oberrand an die Seitenocellen stösst, dessen Unterrand über den Antennen liegt und dort von einer geraden scharfen, gelblichen Linie begrenzt wird. Auch in der Mitte der Augen und hinter denselben sind noch Spuren des Bandes zu sehen. Augen gross, kuglig, vorstehend. Antennen wenig länger als Kopf und Pronotum, vor dem Ende leicht angeschwollen, undeutlich geringelt. Pronotum fast glatt oder leicht gerauht, eingezogen; Hinterrand rechtwinklig, etwas gewellt (Fig. 12 a), kaum abgerundet, Vorderrand etwas eingeschnitten, besonders in der Mitte, Hauptquerfurche vor dem ersten Drittel der Länge, beim ơ hinter demselben, wie die beiden andern von geringer Tiefe; Seitenlappen höher als lang, oft mit einer schwarzen Längsbinde in der Mitte ${ }^{1}$ ), die namentlich beim gut ausgebildet ist, Vorderwinkel spitz, Hinterwinkel stumpf gerundet, Vorder-, seltener auch der Hinterrand, dunkel gefleckt. Elytren viel länger als der Körper, mässig breit, schwach gebogen mit rundem Ende, im letzten Drittel hyalin, mit 2 grau- bis braunschwarzen Querbinden, seltner Spuren einer dritten; die Grenzen derselben dunkler als ihr Innentheil, ununterbrochen, scharf gewellt, unregelmässig verlaufend, nur die proximale Grenze der ersten Binde sich im Grundton der Basis der Elytren verlierend (Taf. I, Fig. 14); der Apicaltheil mit sehr verwaschenen grauen Fleckchen; Intercalarader auf ihrer ganzen Länge der hintern Radialader mehr als der Ulnarader genähert. Flügel hyalin, mit licht-schwärzlicher, hinten bald verschwindender Binde, welche den blauen Basaltheil von der ungefärbten Flügelspitze trennt. Die beiden ersten Beinpaare geringelt;

1) Ein Männchen trägt eine solche auch an der Grenze von Discus und Seitenlappen. 
Hinterschenkel gedrungen breit, mit hoher, scharfer Ober- und Unterkante, im letzten Drittel und am Ende mit je einem schwarzen, auf die Innenseite übergehenden Flecken; der breite Theil der Innenfläche tief blauschwarz. Aussentheil der Schenkelunterseite mit einem blau beginnenden, am Ende des zweiten Drittels der Länge schwarz aufhörenden Längsfleck; Hintertibien mit Ausnahme des innen schwarzen Gelenkkopfes Anfangs gelb, dann bläulich. Supraanalplatte dreieckig, Subgenitalplatte des $q$ in der Mitte des Hinterrandes keilförmig ausgeschnitten; Cerci lang, besonders beim đ̃ , schwach conisch.

\begin{tabular}{|c|c|c|c|c|c|c|}
\hline änge & des & Kö1 & $13,5-15$ & $\mathrm{~mm}$ & $22-25$ & $\mathrm{~m}$ \\
\hline 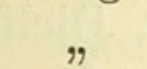 & & Pror & 3 & & $4-5$ & \\
\hline & del & Elytren & $16-1$ & & $21-24,5$ & \\
\hline & & Hinterschenkel & $8-8,5$ & & $11-12,5$ & \\
\hline
\end{tabular}

Fundorte: Aumale 9./7. 97, Bouira 16./7.

Von allen bekannten Sphingonoten unterscheidet sich diese neue, vielleicht auf das Gebiet in der Umgebung des Djurdjura beschränkte, Species sofort durch die eigenartige schwarze Stirnbinde, die Zeichnung der Elytren und Hinterschenkel, sowie durch die Zartheit der Sculptur an Kopf und Pronotum.

\section{Sphingonotus balteatus (SERv.).}

Weit verbreitet (Indien, Syrien, Aegypten, Süd-Afrika), aber aus Algerien noch nicht erwähnt. In der Färbung von licht gelbbraun bis hoch rost- oder kupferroth, ferner bis grau und graugelb variirend, einzelne algerische und tunesische Exemplare auf Kopf, Pronotum, Basaltheil der Elytren und Hinterschenkel schwarz punktirt. Die Veränderlichkeit der Binde auf dem Flügel erstreckt sich hauptsächlich auf deren Ausdehnung gegen die Wurzel zu, wo deren Farbe allmählich verwaschen wird, und gegen den Hinterrand, wo die Binde sich bald verbreitert, bald verschmälert. Oft wird die hyaline Flügelwurzel bis auf einen kleinen Rest verdrängt, ihre bläuliche Färbung verschwindet. In einigen Fällen sind die Hauptaxillaradern tief schwarz, fast stets aber die Nebenäderchen in der Uebergangsfärbung. Die Breite des von der Binde freien Flügelhinterrandes variirt von $1 / 4-2 \mathrm{~mm}$. Trotz dieser Veränderungen bleibt die Art stets gut kenntlich; von über 110 Exemplaren aus verschiedenen Gegenden kann keines mit einer der nahestehenden 
Arten verwechselt bezw. als Uebergang dazu angesehen werden. Die Grösse scheint sich nach der Gegend des Vorkommens zu richten, nach Westen und Norden abzunehmen. Die grössten Thiere von Süd-Tunesien (Länge der $q$ von Gafsa und Gabès 28 mm, der Elytren $27 \mathrm{~mm}$ ) bleiben weit hinter den von de Saussure aus den Eingangs angeführten Fundorten stammenden Individuen (30 bezw. $39 \mathrm{~mm}$ ) zurück.

Aus Aegypten erwähnt De Saussure (Additam. p. 86) eine Varietät mit rosenamaranthfarbener Flügelwurzel.

Finot's Angabe (l. c. p. 468 u. 476), dass das Pronotum „bien rugueux" sei, kann sich nur auf Ausnahmen beziehen und erschwert die Bestimmung nach seiner Artenzusammenstellung.

Fundorte: Mecheria (Oran) 7. $92^{1}$ ), Aumale 10./7. 97, Djelfa 3./7., Sidi Maklouf 28.6. (Nachtfang), Bou Saâda 7./7., Laghouat 20.-22./6., Bir bou Rekbah 26.6. 01, Hammam el Lif 28.6., Sousse 12.6., Sfax 23.6., Graïba 19.6., Gafsa 20.-22.6., Gabès 15.6.

\section{Sphingonotus savignyi SAUSS.}

Die beiden Binden der Elytren am dunkelsten, oft schwarz, vor der Radialader, auf dem Flügel der $\delta \delta$ kann die Binde sehr schmal, zugleich hellbraun werden. Für Algerien bildete Biskra nach Finot, de Saussure, Brunner den einzigen Fundort; 1897 wurde auch in Laghouat (20./7. 97) ein durch stark angerauchte Spitzen der Flügel ausgezeichnetes Exemplar (Stirps apicalis Sauss. Prodr. p. 208) von mir gefangen. Häufig tritt diese schöne grosse Art in der nächsten Umgebung des Bahnhofs von Gafsa (20.-22.6. 01) auf, mit Dimensionen, die denen der Var. major Sauss. (Additam. p. 84) entsprechen. Die +9 sind in der Frühe leichter zu erbeuten als Nachmittags, wo sie zwischen $3-5$ Uhr so scheu sind, dass es kaum gelingt, sich ihnen auf mehr als 8-10 Schritte zu nähern. Das Zirpen der ơ klingt eigenthümlich trocken, wie wenn man mit einem Stäbchen über ein dürres Blatt streicht oder leicht klopft, je 3 Schläge hinter einander. Das Gebiet der Verbreitung erstreckt sich über Süd-Algerien und Tunesien, Aegypten nach Persien und Kashmir, selbst auf den Canaren kommt eine kleinere Abart (stirps canariensis Sauss. Prodr. p. 208) vor.

1) Nachträglich erst unterschieden. 


\section{Sphingonotus octofasciatus (SERV.).}

Im Habitus der vorigen Art sehr ähnlich, durch ihre bedeutende Grösse und prachtvoll rothe Färbung der Flügel von allen nordafrikanischen Sphingonoten unterschieden. Ebenfalls weit verbreitet (Kirgisensteppe, Aegypten, Algier, Tunis), aber mehr dem Gebiet der Wüste angehörend, und auf den Süden beschränkt, nirgends häufig.

Fundorte: *Bou Saâda 5./7. 97, Gafsa 20.-22.6. 01 (sehr grosse Exemplare [Länge der Elytren $35-36 \mathrm{~mm}$ ] mit intensiv rothen Flügeln).

Bemerkenswerth ist der Reichthum an Arten von Sphingonotus in dem verhältnissmässig kleinen Gebiet.

In seinen mehrfach citirten Arbeiten führt DE SAussure im Ganzen etwa 32 Formen auf, welche im günstigsten Falle 26 gute Arten bilden. Finot kennt aus Nord-Afrika 10 Species, wovon 1 (Sph. sefrae) als Varietät zu betrachten ist, 3 in meinen Ausbeuten fehlen. Dafür enthalten diese - unter Einrechnung des früher als Varietät beschriebenen Sph.mecheriae und hucasii, sowie des vonHelioscirtus herübergenommenen Sph.finotianus - 4 neue, im Ganzen 10 gute Arten und 1 Varietät, also nicht viel weniger als die Hälfte der bekannten Arten. Ihre grösste Entwicklung weist die Gattung in der Steppe und Wüste auf. Etwa 4 Arten scheinen ganz ausschliesslich dort zu leben; die an den Küsten anzutreffenden dringen mit wenigen Ausnahmen bis zu den südlichsten besuchten Punkten vor. Jenseits des grossen Atlas sind, nach zahlreichen Larven zu schliessen, mit ziemlicher Sicherheit in den Sommermonaten noch verschiene neue, vor Allem kleine Arten zu erwarten.

Obgleich Spaniens Orthopterenfauna so ungemein viele Berührungspunkte mit der nord-afrikanischen besitzt, umfasst sie nach dem neuesten Verzeichniss Bolivar's ${ }^{1}$ ) doch nur 3 (bzw.4) SphingonotusArten.

\section{Leptopternis dE SAUSSURE.}

Von der Gattung Sphingonotus trennte DE Saussure (Addit. ad Prodr. Oedip. u. Mitth. entom. Ges. Schweiz.) eine Anzahl meist

1) Bolivar, J., Catalogo sinóptico de los Ortópteros de la Fauna Iberica, in: Annaes Sc. natur. Porto 1897-1899, Coimbra 1900. 
kleiner, durch stark verlängerte Enddornen der Hintertibien ausgezeichneter Arten, für welche die Gattungen Leptoscirtus, Leptopternis und Conipoda aufgestellt wurden. Die meisten derselben sind offenbar Glieder der Wüstenfauna, dem entsprechend sandfarben, d. h. auf gelbem bis röthlichem Grundton mit kleinen dunklern Fleckchen versehen; die Flügel meist ohne Zeichnung, hyalin, gelblich oder bläulich; Pronotum entweder höckerig wie bei Sphingonotus oder eigenthümlich verkürzt, gedrungen und dann beinahe glatt (Leptopternis, Leptoscirtus), aber eingezogen, Metazone kurz. Die Gattungen sind noch nicht scharf umgrenzt. Leptoscirtus unterscheidet sich von den beiden andern durch die ungewöhnlich stark seitlich zusammengedrückte, unterhalb der Ocelle verschwindende Stirnleiste, den eigenartigen Bau der kurzen 9 gliedrigen Fühler, deren letztes Glied aus einer Anzahl mit einander verschmolzener besteht und die langen, schmalen, gegen das Ende sich zuspitzenden Elytren. Die Form der Enddornen der Hintertibien giebt das Hauptmerkmal für Leptopternis und Conipoda ab, sie sind dort lang, leicht gebogen, hier dick, am Ende scharf, winklig gekrümmt. So unähnlich die beiden im Folgenden als neu beschriebenen Arten im ganzen Habitus sind, so können sie doch zunächst nur in die Gattung Leptopternis eingereiht werden.

\section{Leptopternis maculata $n$. sp.}

(Taf. 17, Fig. $14 \mathrm{a}, \mathrm{b}-15$ u. Textfig.)

Klein, schlank, lichtgelb- bis röthlich-braun. Kopfgipfel nur wenig vorstehend. Scheitel flach, abschüssig, an den Seiten leicht gekielt. Stirngrübchen undeutlich dreieckig, Stirnleiste mit deutlichen Seitenkielen, unter- und oberhalb der Ocelle verschmälert. Antenne dünn, 1/2 mal so lang wie Kopf und Pronotum zusammen, dunkel und hell geringelt. Pronotum kurz und breit, mehr oder weniger rauh, Vorderrand oft gekerbt, Hauptquerfurche genau im ersten Drittel, beim ठ etwas weiter zurückliegend, Mittelkiel nahe dem Vorderrand stark erhaben, zwischen der ersten und Hauptfurche aufgelöst, auf der Metazone nur schwach; Metazone vertieft punktirt mit schwach gerundetem Hinterrand; Seitenlappen höher als breit, mit schrägem, leicht gewelltem Unterrand, Winkel ausgezogen abgerundet-spitz. Elytren lang, gegen das gerundete Ende sich verschmälernd, leicht gebogen, ohne ausgeprägte Binde, mit zerstreuten dunklern Flecken, die auf den distalen 3 Vierteln des Marginalfeldes fehlen. Intercalarader der hintern Radialader genähert, Axillar- 
ader nicht frei. Flügel hyalin, an der Wurzel bläulich mit einem dunkeln Flecken von wechselnder Grösse und Intensität zwischen der Vena dividens und der dritten dicken Axillarader, selten mit einem zweiten kleinen im vordern Flügelfeld, als Resten einer Binde. Oberkante der Hinterschenkel mit Andeutungen von 2-4 Binden,

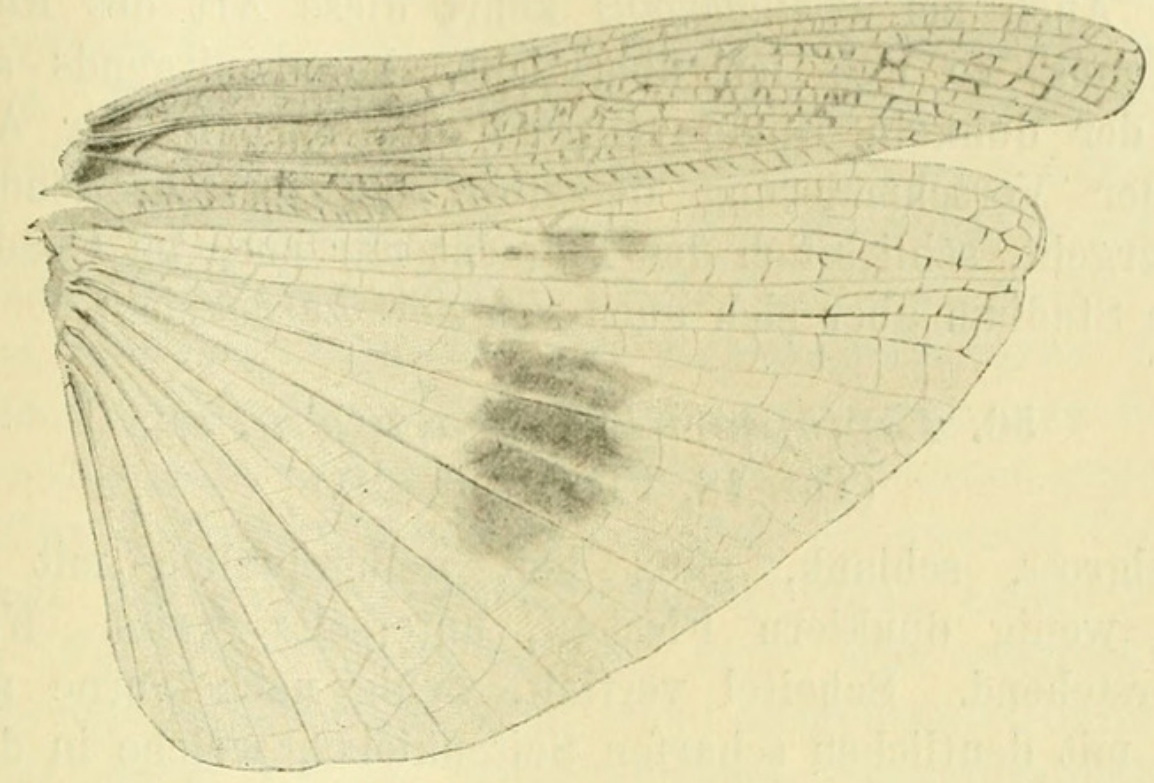

Flügel von $L$. maculata. $4: 1$.

Hintertibien im Anfang gelblich, dann hellblau, ohne schwarzen Flecken unterhalb des Gelenkknopfes, innere Enddornen (Fig. 15) fast so lang wie das erste Tarsalglied, auf der diesem zugekehrten Seite mit Börstchen. Supraanalplatte gerundet dreieckig, untere Vaginalplatten mit einem kaum auffallenden, hellen ventralen Höckerchen.

\begin{tabular}{|c|c|c|c|c|c|}
\hline & & c & & q & \\
\hline Länge & des Körpers & $13-15$ & $\mathrm{~mm}$ & $18-19$ & $\mathrm{~mm}$ \\
\hline. & „Pronotums & $2,5-3$ & $"$ & $3,5-4$ & " \\
\hline & der Elytren & $13-14$ & $"$ & $18-20$ & \\
\hline & „Hinterschenkel & 8 & , & $11-11,5$ & \\
\hline
\end{tabular}

Fundorte: Bou Saâda 5./7. 97, Laghouat 22.6., Gafsa 22./6. 01, Graïba 19./6. Lebt stets auf sterilem sandigem Grund; ein Exemplar flog nach starkem Sturm an dem Lichte an.

Die Art besitzt, wie auch L. imitans (Br.), so viel Aehnlichkeit mit Sphingonotus, dass sie eigentlich nur durch die Länge der tibialen Enddornen davon getrennt ist. Der Bau und die Proportionen von Kopf, Pronotum und Flügeln sind geringen Schwankungen unter- 
worfen, vor allem kann der Vorderrand und die Prozone des Pronotums glatter sein als in den Abbildungen. Ob hier ein Bindeglied zwischen Sphingonotus und Leptopternis vorliegt, wäre noch zu entscheiden.

Von allen bekannten Gliedern der Gattung ist dieses neue durch den dunkeln Flügelfleck unterschieden und darum kaum zu verwechseln. Auch bei Sphingonotus kehrt diese Art des Rückgangs der Zeichnung, so weit ich überblicken kann, nirgends auf; der Schwund der dunkeln Binde vollzieht sich dort in der Art, dass neben einer Verschmälerung derselben ein fortschreitendes Verblassen hergeht, schliesslich das Pigment nur noch im Geäder liegt, im letzten Stadium aber sich auch von dort zurückzieht.

\section{Leptoptermis calcarata $n$. sp.}

(Taf. 18, Fig. 9a,b-10.)

Mittelgross, schlank, ganz hell gelbbräunlich mit unregelmässigen, wenig dunklern Flecken, unterseits weiss. Kopfgipfel wenig vorstehend. Scheitel vertieft, wenig nach vorne abfallend (Fig. 9a), mit deutlichen scharfen Seitenkielen, welche in der Mitte des obern Augenrandes endigen. Stirne nach unten sich rasch verbreiternd, Stirnleiste in den Scheitel übergehend, schmal, mit erhabenen, fast parallelen zierlichen Seitenkielen, punktirt, unterhalb der Ocelle verschwindend. Stirngrübchen meist kaum angedeutet. Augen gross, kuglig, besonders beim đ stark vortretend, wenig von einander entfernt. Antennen lang, etwa 23 gliedrig (die letzten 2-3 Glieder nicht deutlich getrennt), fadenförmig, Anfangs weisslich, nach aussen bräunlich gefärbt. Stirne, Wangen und Mundwerkzeuge fast rein weiss, theilweise mit vertieften Punkten, Scheitel und Hinterhaupt von der Grundfarbe, mit unregelmässigen dunklern, auf dem Scheitel etwas vertieften Flecken. Pronotum gedrungen, wenig höckerig, nach unten sich verbreiternd, Hauptquerfurche hinter dem ersten Drittel, Mittelkiel sehr schwach, von den Furchen der Prozone unterbrochen, aber zwischen diesen nicht aufgelöst, Metazone fein punktirt, wie die Prozone zart und unregelmässig gefleckt. Hinterrand zugespitzt, beim $\delta$ in der Mitte etwas mehr abgerundet als beim ๆ. Seitenkiele fehlen vollständig, Seitenlappen stark gefurcht (Fig. 9 b). Wie ihr Unterrand schräg, stark ausgebuchtet, die Winkel abgerundet. Elytren schmal, gestreckt, linear, am Ende sich verjüngend, Anfangs derb, in den äussern ${ }^{3} / 4$ mehr oder weniger hyalin, vor allem beim $\delta$, das Geäder weisslich-gelb, zwischen der 
Vena dividens und dem Hinterrand eine Reihe verwaschener Flecken, sonst nur ganz unbestimmte Spuren solcher, die Flügelspitze aber ganz ohne Zeichnung bis kurz vor dem Hinterrand. Area mediastina, scapularis und axillaris mit falschen Adern. Hintere Radialader sich vor dem Stigma rasch von der mittlern entfernend. Stigma beim $q$ undeutlich, beim of fehlend. Intercalarader gegen das Ende gebogen, auf der ganzen Länge der hintern Radialader genähert. Axillarader nicht frei. Flügel sehr schlank, an der Spitze wenig abgerundet, hyalin, vollkommen frei von Abzeichen oder dunklern Adern. Hinterschenkel schmal, schlank, oberseits mit einer Reihe röthlich- bis graubrauner Fleckchen, Aussen- und Unterseite weiss, Innenseite fleckenlos, gelblich, Oberseite der Gelenkkapsel grau überflogen; Hintertibien gelbweiss mit Ausnahme eines blaugrauen Fleckes aut der Innenseite unterhalb. dem Gelenkknopf, Enddornen ungemein lang und kräftig, die innern erreichen das Ende des zweiten Tarsalgliedes, sind leicht und ziemlich gleichmässig gebogen, Länge wenig verschieden (Fig. 10). Tarsus zierlich, nicht sehr gestreckt. Supraanalplatte jederseits vor dem Ende leicht ausgebuchtet, untere Vaginalplatte mit einem kleinen Seitenzähnchen, Subgenitalplatte in der Mitte mit einer Endfurche (vielleicht beim Trocknen entstanden). Cerci in beiden Geschlechtern lang, kegeltörmig.

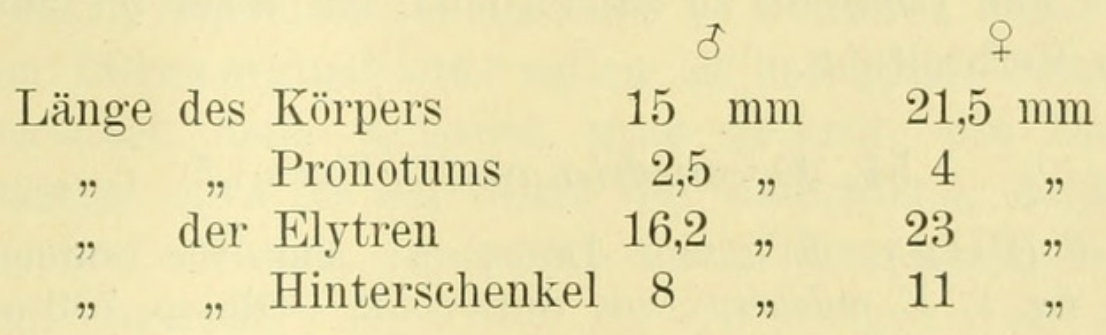

Nahe verwandt mit $L$. canescens Sauss. und $L$. rhamses Sauss. unterscheidet sich jene Art von der neuen durch die Form der Seitenlappen des Pronotums, deren Hinterwinkel „in acumen producti“, deren Unterrand geradlinig schräg verläuft. Auch im Geäder der Elytren und Flügel finden sich Unterschiede, namentlich fehlt letztern bei $L$. calcarata die Verdickung der „Venae radiatae principales $1 \mathrm{a}-4$ a vel $5 \mathrm{a}$ " und die einfache Lappung des Hinterrandes. Endlich ist $L$. canescens bedeutend grösser, das o erreicht die Dimensionen des $ᄋ$ von $L$. calcarata.

Die zweite Art, L. rhamses, ist durch kürzere Fühler, plumperes Pronotum mit einer weniger langen Metazone, weniger schlanke, am Ende mehr abgerundete Elytren und Flügel und durch die gedrungenern Hinterbeine ausgezeichnet. 
Durch das freundliche Entgegenkommen Herrn Hofrath Brunner's war es mir möglich, 2 weitere Arten zu vergleichen, nämlich L. imitans (Br.) und $L$. clausii (Кітт.). Die erstere (aus Granada) ist kleiner, viel gedrungener, zudem in der Plastik des Kopfes und Pronotums verschieden, die zweite (von Astrachan) trägt viel eher den Habitus der L. calcarata, ist aber im weiblichen Geschlecht kleiner, im männlichen grösser als diese, besitzt verdickte Axillaradern der Flügel und die Enddornen der Hintertibien sind noch länger als die beiden ersten Tarsalglieder. Die fünfte von DE SAussure veröffentlichte, Art endlich, L. gracilis, hat 17 gliedrige Antennen.

Fundort: Bou Saâda 5./7. 97; im Ganzen nur $1 q$ und 2 ỡ auf den Dünen nördlich der Stadt gefunden, denen ihre Färbung vollkommen entsprach.

Die Gattung erstreckt sich über ein sehr weites Verbreitungsgebiet. $\mathrm{Zu}$ den bekannten Fundorten aus Turkestan, Astrachan, Granada und Aegypten kommt Algerien und Tunesien ${ }^{1}$ ) hinzu und zwar so weit daselbst heisse Steppe oder Wüste vorherrscht. Sehr wahrscheinlich sind die gefundenen Arten nur die nördlichsten Vertreter einer ausschliesslich dem Wüstenleben angepassten Gruppe kleiner bis mittelgrosser Sphingonotiden, zu denen die Gattungen Leptoscirtus und Conipoda zu zählen sind, mit einer bis zum Senegal reichenden Verbreitung.

\section{Eremobia cisti (FABR.). $\left.{ }^{2}\right)$}

Gryllus cisti (FABR.), E. claveli Luc., in: Ann. Soc. entomol., 1851, tab. 8, fig. 1, E. pulchripennis, Serville, Orth., p. 708 u. SAvigny, in: Descr. de l'Egypte Orth., tab. 7, Fig. 16.

Von den meisten Autoren werden aus Nord-Afrika mit Einschluss von Aegypten 3 Arten der Gattung Eremobia aufgeführt. Aus den Angaben ist die Schwierigkeit der Abgrenzung ersichtlich, und Brunner vereinigt im Prodromus p. 183 E. cisti F. und clavelii Luc. hält dagegen die ägyptische E. pulchripennis SERv. für eine gute Art. Eremobia ist aber dermassen veränderlich, in Grösse, Farbe und Form so auffallend von der Umgebung beeinflusst, dass man beinahe

1) Wie obon gezeigt wurde, gehört der von dort als einziger Vertreter aufgeführte Leptoscirtus(?) einer andern Gattung an.

2) Zur Illustration der Variabilität der nord-afrikanischen Eremobien wird der zweite Theil dieser Arbeit eine eigene Tafel mit erklärendem Texte bringen. 
für jeden Fundort eine neue Art oder wenigstens eine neue Varietät beschreiben könnte; die $\delta \delta$ sind stets weniger verschieden als die q⿻, ihre Flügel kräftiger gefärbt. Von 11 nord-afrikanischen Fundorten sammelte ich im Ganzen gegen 90 Exemplare, welche leichtlich auf 4-5 Arten vertheilt werden könnten, wenn nicht für jede scheinbar specifische Eigenschaft oft an einem und demselben Ort Uebergänge nachzuweisen wären. Im Westen Algeriens traf ich die Art häufiger an als im Centrum oder gar in Tunesien; ihre Zahl nahm im Departement Oran und Alger nach Süden zu. Während in Mecheria, Aïn Sefra, Tiout, also schon am Rande der Sahara, ausschliesslich grosse kräftige Thiere gefunden wurden, beherbergen die östlichen entsprechenden Localitäten (Laghouat, Gabès) kleine zierliche Localformen, wie sie in nördlichen Gebieten nie vorkommen. Die gewöhnlichere Form aus dem Süden Orans ist entweder mit langen oder ziemlich verkürzten kaum die Hinterschenkel überragenden Flugorganen ausgestattet. Die Färbung der 우 (seltener der $ठ \delta$ ) ist entweder ein gleichmässiges Kupferbraun ohne besondere Abzeichen auf Kopf und Pronotum, mit nur verwaschenen Tonflecken auf den Elytren und Hinterschenkeln, oder es treten die bekannten Zeichnungen auf den genannten Körpertheilen scharf hervor; die Erhöhungen des Mittelkiels auf der Prozone des Pronotums stets scharf, beim ơ regelmässiger als beim ণ, Metazone rauh, sandig, mit erhabenem Intramarginalrand; selten ist das ganze Pronotum lederartig, geglättet, dann weisslich grau gefärbt; die Innenseite der Hinterschenkel etwa bis zur Mitte tief dunkelblau, dann wie Oberund Unterrand hellgelb, Innenseite der Tibien gelblich, selten mit einer Spur von roth.

Bei einigen Larven ist der von Blau freigelassene Theil der Hinterschenkel und die Innenseite der Tibien prächtig roth. Exemplare von Bou Saâda gleichen der lang geflügelten scharf gezeichneten Form, die Hintertibien aber sind beim $q$ innen intensiv roth, beim o gelb. Um Djelfa herrscht eine in beiden Geschlechtern gleich gefärbte, fast zeichnungslose, stumpf lichtbraune Form mit hell- bis citronengelben Tibien vor. Auffallend weicht die Eremobia von Laghouat von der der übrigen Fundstellen ab, besonders im weiblichen Geschlecht: sie misst nur 38-40 statt $45-50 \mathrm{~mm}$, die Farbe (beim $\delta$ ebenso wie die Zeichnung kaum von der andrer Orte verschieden) ist hell braungrau mit wenigen verwaschenen Tonflecken auf den Elytren und Hinterschenkeln, die Sculptur des Pronotums ist glatter, verflacht, Pro- und Metazone wiederum ab und zu lederartig 
(var. Taeviuscula Krauss) ${ }^{1}$ ); Flügel ganz blass rosa, die dunkle Binde kaum mehr als angehaucht, unterbrochen; Hinterschenkel auf der Innenseite bis zu $2 / 3$ leuchtend blau mit Einschluss des Ober- und Unterrandes, Innenseite der Tibien lichtgelb bis hellzinnoberroth.

In Bir bou Rekbah, nahe der ost-tunesischen Küste, erhielt ich ferner ein Pärchen mit sehr verkürzten Flugorganen und schwach ausgeprägter Zeichnung; die Flügel des Weibchens ebenfalls blassrosa mit verschwindender Binde; Elytren des of sehr verbreitert. Das Blau der Hinterschenkel erreicht kaum die Mitte der Innenseite, Hintertibien innen roth.

Die zierlichste Localform (var. gracilis Sauss.?) ist die von Gabès. Sie ist noch kleiner als die von Laghouat, welcher sie in Farbe und Zeichnung sehr gleicht, von der sie sich aber durch intensiver roth gefärbte Flügel, nahezu ganz schwarzblaue Innenseiten der Hinterschenkel und schwarzrothe der Tibien, auf denen nur der Anfang und das Ende roth, die Enddornen gelb sind, unterscheidet.

Eine weitere, sehr interessante Form aus dem Oued Mzab bei Ghardaja kann ich dank einer freundlichen Zuwendung von Herrn Dr. Krauss hier anfügen. Es ist dies ein in allen Stücken mit meinen Individuen aus Laghouat übereinstimmendes Thier, dessen Flügel aber statt roth blau gefärbt sind, und zwar wie gewöhnlich beim of deutlicher als beim o; von der dunklen Binde sind bei diesem nur noch ganz schwache Spuren vorhanden.

In dieser kleinen Blütenlese über die Veränderlichkeit der nordafrikanischen Eremobien sind so ziemlich die meisten von DE SAUssure erwähnten Varietäten mit einbegriffen, ebenso die E. pulchripennis (SERv.). Es lässt sich also zeigen, dass zwischen den bisher getrennt gehaltenen Arten alle möglichen Uebergänge vorhanden sind, auch bezüglich der hier nicht besonders hervorgehobenen Merkmale nirgends Grenzen gezogen werden können. Ob man die unterschiedenen Formen als Varietäten oder Localrassen aufrecht erhalten will, ist noch zu entscheiden, als „gute Arten“ aber wird man sie nach dem mitgetheilten nicht mehr weiterführen.

Die Verbreitung von Eremobia ist eine sehr ausgedehnte, reicht bis Central-Asien und Süd-Afrika. In beiden Richtungen ist die Gattung durch eine ganze Anzahl Arten vertreten, welche ebenfalls mehr oder weniger variiren. Als Grund der Veränderlichkeit be-

1) Krauss, H., Dermapteren und Orthopteren aus Tunis, in: Wien. entomol. Ztg., Jg. 11, Hft. 5, 1892, p. 149. 
trachtet DE SAussure mit Recht die exponirte Lebensweise auf weiten, fast vegetationslosen Flächen, welche, kaum einen Versteck bietend, die besonderer Vertheidigungsmittel entbehrenden Thiere zur grösstmöglichen Anpassung zwingen.

Das Vorkommen von E. cisti in Spanien und Portugal scheint nach den jüngsten Mittheilungen von BoLrvar (Catalog p. 78) fraglich. Ueber die beiden darauf bezüglichen Angaben von LatreiLle und Fieber wird daselbst gesagt: Lo probable es que ambas citas se refieran a la $C$. (Cuculligera) flexuosa Serv. si no son hijas de un error ó equivocacion de etiqueta. E. claveli soll nach Finot (p. 486) Tunis und die Wüstenregion bewohnen; Lucas aber entdeckte sie auf dem Hochplateau von Boghar, nicht sehr weit im Süden von Algier, auf unbebautem sandigem Boden (1851, p. 370).

Fundorte: Bou Saâda 7.7. 97; Djelfa 3./4.; Laghouat 22./6.; Bir bou Rekbah 26.6. 01, Gabès 17.6.

\section{Pyrgomorpha grylloides (Latr.).}

(Textfig.)

Nach wiederholten Vergleichungen stellte es sich heraus, dass sich unter meinem früher gesammelten Material 2 Arten befinden, welche sehr leicht zu verwechseln, gewöhnlich jedoch geographisch getrennt sind. $P$. grylloides ist vorwiegend im algerischen Tell zu treffen, nur einmal fand ich sie im Süden Orans; aus Tunesien kenne ich sie nicht, sie scheint dort durch die folgende Art ersetzt zu sein. Meine frühern Angaben über die Verbreitung sind folgendermaassen $\mathrm{zu}$ berichtigen:

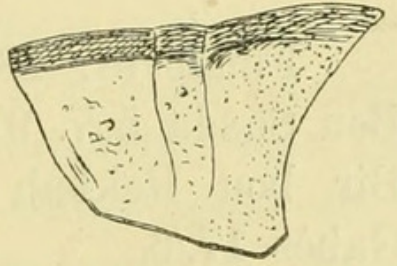

Pronotum von P. grylloides von der Seite. Vergr. 4: 1 . Perrégaux, Hammam bou Hadjar, Er Rahel, Rio Salado, Saïda, Aïn Sefra. Hiezu kommt noch der Fundort: Medeah 15.5. 97. Die oq sind alle grün, die ỡ braun gefärbt.

\section{Pyrgomorpha cognata Krauss.}

(Textfig:)

P. cognata Krauss, Orth. v. Senegal, p. 58; Savigny, Descript. de l'Egypte, tab. 6, fig. 5.

Unterscheidet sich von der vorhergehenden Art durch viel schlankere, hauptsächlich auf der geringern Breite der Brust beruhenden Statur, durch einen gebogenen Unterrand der Seitenlappen 
des kleinern Pronotums, deren Winkel scharf ausgeprägt, selbst ausgezogen (hinterer Winkel, vgl. beistehende Fig.) sind. Der Kopf ist

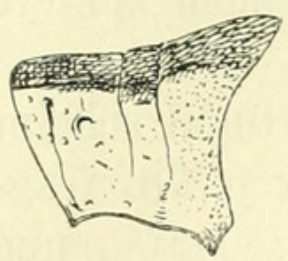

Pronotum von $P$. cognata von der Seite.

Vergr. $4: 1$. schmäler, die Augen grösser, die Seitenkiele des Pronotums nur vor der ersten Querfurche deutlich hinter derselben entweder fehlend oder verschwommen; auch der Mittelkiel nicht so stark wie bei $P$. grylloides. Die Elytren sind verschmälert, relativ sehr lang, am auffallendsten bei den Individuen aus Tiout $(q 23$, $\delta$ $15 \mathrm{~mm})$ und Aïn Sefra, grün oder braun, selbst gelbroth, alle Töne ab und zu neben einander an einem Fundorte, die braunen gewöhnlich mit hellern oder dunklern Längssprenkeln gemischt, die ơ sind stets braun; Flügel häufig ohne Farbe oder statt des lebhaften Roths mit zartem Violett (Djelfa). In den Körperproportionen weicht $P$. cognata von $P$. grylloides (Zahlen rechts in Klammern) constant ab:

Länge des Körpers

. $\quad$ Pronot.

der Elytr.

"Hinterschenkel 7-8,

$14-17 \mathrm{~mm}(17,5)$

$2,9-3,2, \quad(3,5)$

,

,

Fundorte: 1894 Khreider, Mecheria, Aïn Sefra, Tiout, ferner Bou Saâda 5.7. 97, Djelfa 3.7., Laghouat 22.6.; Goulette 5.6. 01, Bir bou Rekbah 26.6., Sousse 12.6., Sfax 23.6., Graïba 19.6., Gabès 17. 6 .

Kommt mit der vorhergehenden nur an einem Ort (Aïn Sefra) zusammen vor, beherrscht den Süden Algeriens und die Ostküste Tunesiens, reicht weit in die Wüste, wo sie Dr. Krauss noch in Tuggurt, Ghardaja und Blidet Amar fand. Da es sich kaum feststellen lässt, ob nicht manche Angabe über das Vorkommen der P. grylloides sich auf diese Art bezieht, kann über die weitere Verbreitung nichts angegeben werden, als dass sie in Aegypten vorhanden sein muss und von SAvigny gut abgebildet ist.

Den so ganz charakteristischen Verlanf des Unterrandes der Pronotumseitenlappen hat KRauss in seiner Diagnose nicht erwähnt, wohl aber Bolivar in seiner Monographia de los Pirgomorfinos, Madrid 1884 (nach brieflicher Mittheilung von Dr. Krauss) hervorgehoben. Er allein kann schon die Unterscheidung der Arten ermöglichen; dazu kommt noch der stets schlankere Habitus von $P$. 
cognata, die ich demgemäss für eine gute Art halte, um so mehr, als Uebergangsformen bislang fehlen.

\section{Pyrgomorpha debilis Fin.}

Zur Entscheidung der Frage, ob diese flügellose Art nicht etwa besser (nach BrunneR's Ansicht) unter die Gattung: Sphenacris zu rechnen sei, vermag ich nichts beizutragen. Von Brunner bei Aïn Sefra entdeckt und bis jetzt nur von dort bekannt, scheint sie auf den äussersten Süden Nord-Afrikas beschränkt und selten zu sein, wurde von mir auch in Laghouat (24.6.) als Larve angetroffen. Die Form des Unterrandes des Pronotums ist der von $P$. cognata sehr ähnlich.

\section{Ocnerodes canonicus (FISCH.).}

Bezüglich der Unbeständigkeit der Artkennzeichen bilden die Pamphagiden ein Seitenstück zu den Eremobien. Voraussichtlich wird nach weitern Untersuchungen eine Reduction der 5 von Finot aufgeführten Ocnerodes-Arten auf 2 eintreten, vielleicht gar nur 1 anerkannt werden können. In meinem ältern Material aus Oran befinden sich alle Zwischenstufen zwischen O. volxemi BoL. und longicornis BoL., d. h. den beiden durch den Mangel eines Zahnes auf der Vorderrandsmitte des Prosternums ausgezeichneten Arten. Die Ausbildung der Elytren, wenn sie überhaupt vorhanden sind, ist sehr wechselnd. Dasselbe dürfte für die 3 mit einem mehr oder weniger deutlichen Zahn auf dem Prosternum versehenen Arten O. micropterus (BRIS.), nigropunctatus (LUC.) und canonicus (FISCH.) gelten, womit der Werth eines der hauptsächlichsten in der Tabelle der Arten von Fгхот benutzten Merkmale hinfällig wird. Die wenigen von mir Anfangs Juni 1901 auf den Hügeln um Tunis gefundenen Exemplare sind graubraun, ohne Abzeichen (ઠ) oder dunkel braunschwarz mit hellen gelblichen Schrägfleckchen auf den Seiten der Abdominalsegmente (+). Die Art wurde bei Tunis schon öfters gefunden.

\section{Pamphagus expansus BR.}

Scheint wie seine nächsten Verwandten $[P$. algericus (BR.), simillimus (YERs.) und mauritanicus (BoL.)] mehr auf das Littorale beschränkt, gehört vielleicht mit diesen unter $P$. tibialis (Fıвв.) vereinigt (FINOT). 
Fundorte: Dra el Mizane 19.8. 97, Aumale 10.7. Neben erwachsenen Thieren fanden sich hier zahlreiche ganz junge, vielleicht einer 2. Generation angehörence Larven.

\section{Pamphagus mülleri Krauss.}

Von Krauss (1896) als "Diminutivform“ von P. hespericus (Raмв.) bezeichnet, von Fiмот als wahrscheinlich zu $P$. saharae gehörig angesehen, kehrt in der bei Mecheria (Oran) gefundenen typischen Form bei Laghouat wieder. Die Unterschiede zwischen diesen dreien sind gering, sie hängen unverkennbar durch nahe verwandtschaftliche Beziehungen zusammen. Der echte schon durch seine bedeutende Grösse auffallende $P$. hespericus bewohnt die Küste, geht aber in Tunis nach Finot von Sfax an südwärts und ins Innere, weicht im Süden Algeriens den beiden andern Arten. Eine Uebergangsform zwischen ihm und saharae nach Gestalt und Grösse wurde bei Bou Saâda angetroffen, in der Form des Kopfes und der Färbung der Hinterbeine mit letzterem übereinstimmend. Die Innenseite der Hinterschenkel ist stets fein blau punktirt, aber nur auf der basalen Hälfte der Fläche; Innenseite der Tibien röthlich-violett bis rothblau.

Fundort: Laghouat 22.6. 97.

\section{Pamphagus saharae Ріст. et Sauss.}

Die Hinterschienen des vorhin erwähnten Exemplares von Bou Saâda auf der Innenseite schwarzblau und weiss gebändert, das Blau sich auf die Innenseite der Dornen fortsetzend, Tarsus lichtbraun. Alle Thiere von Djelfa mit gelben Hinterschienen (innen und oben), Basis der Innendornen wie Spitze blauschwarz. Innenseite der Femora einschliesslich des Unterrandes mit grossen blauschwarzen gegen das Knie hin verschwindenden Flecken.

Fundorte: Bou Saâda 7./7. 97, Djelfa 2./7.

\section{Pamphagus marmoratus Burn.}

Wohl nur eine Varietät des in Algerien und Tunesien ebenfalls verbreiteten, von mir aber nicht angetroffenen $P$. elephas L., d. h. richtiger umgekehrt, denn $P$. marmoratus ist zweifellos der gemeinere und ursprünglichere im ganzen Gebiet der Küste und reicht noch über Sicilien nach Sardinien. Gegen Westen (Oran) wird er häufiger, fehlt in Spanien, geht nach Süden und Osten in eine Anzahl Localformen über, welche ähnlich wie bei $P$. hespericus ebenso- 
wohl als neue Arten wie als Varietäten angesehen werden können. Grösse, Zeichnung, Färbung differiren bei Exemplaren derselben Herkunft nur wenig. Während meine aus Oran stammenden Thiere fast ausschliesslich am Rücken tief dunkelgrün, an den Seiten des Pronotums, Abdomens, am Hinterrand der Segmente kräftig gefleckt sind, erhielt ich bei Aumale ganz hell blassgrüne Exemplare mit wenig auffallender Fleckung, aber von einer solchen Grösse und Dicke wie nirgends sonst. Auch das $\widetilde{\jmath}$, sonst viel intensiver gefärbt als das $q$, ist ganz hell, aber vorwiegend gelb getont.

Fundort: Aumale 10.7. 97 auf Stoppelfeldern in vegetationsreichem Gebiet. Länge des $\%$ bis $92 \mathrm{~mm}$, des § $62 \mathrm{~mm}$.

Mir vorliegende sardinische und sicilianische Exemplare sind gleich den algerischen gefärbt, aber bedeutend kleiner. Krauss (Dermapt. und Orthopt. Siciliens, p. 15) giebt für ơ bis 55, für $q$ bis $82 \mathrm{~mm}$ an.

\section{Pamphagus marmoratus var. tunetanus $n$.}

(Taf. 18, Fig. 3.)

Braun (†) oder gelb, gelbbraun, selten bräunlich olivengrün (ठ), viel kleiner als die Stammform, schlank. Pronotum stark seitlich zusammengedrückt, höckerig rauh, Metanotum sowie die ersten Abdominaltergite mit erhabenen unregelmässigen Leisten, Kopf, Körper und Gliedmaassen mit feinen dunklen Punkten. Fühler 17-18 gliedrig, Glied 3-4 und 8-9 mehr oder weniger deutlich verwachsen. ${ }^{1}$ ) Innenseite der Hinterschenkel blau bis blaugrün gefleckt, Aussenseite mit verwaschenen dunklern Flecken, nicht marmorirt. Oberkante weniger hoch und scharf als bei $P$. marmoratus, undeutlich gesägt, aussen erhaben weiss getüpfelt, wie auch die Unterkante, Hintertibien weissgelb ( $(+)$, gelb (ठ).

$\begin{array}{crrrrr}\text { Länge des } & \text { Körpers } & 45-52 & \mathrm{~mm} & 66-72 & \mathrm{~mm} \\ " & " \text { Pronotums } & 9-11 & & 13-15 & \\ " \quad \text { der Hinterschenkel } & 20-22 & & 23-24 & \end{array}$

Fundorte: Tunis 10./6. 01, Hammam el Lif 28:/6., Bir bou Rekbah 26. 6 .

Die Aufstellung der Varietät ist durch die Gleichmässigkeit

1) Auch bei der Stammform, woselbst aber, ausser 3 und 4, meist $9-10$, seltener $7-8$, verschmelzen. 
der auch aus der Abbildung ersichtlichen Merkmale und durch ihre Verbreitung über eine grössere Strecke gerechtfertigt. In den ältern Beschreibungen ist diese Form vermuthlich hier und da unter $P$. marmoratus einbegriffen, sie wurde auch in der Nähe von Sousse noch beobachtet, lebt gerne auf Oleandern, Zizyphusbüschen oder auf abgeernteten Feldern.

\section{Pamphagus djelfensis n. sp.}

(Taf. 18, Fig. 4-6.)

Nahe verwandt mit $P$. marmoratus bezw. der var. tunetanus, aber kleiner, rauh. Körper des $q$ subcylindrisch, Prothorax wenig zusammengedrückt, Abdominaltergite in der Mitte mehr oder weniger scharf gekielt; sandfarben, hell röthlichgelb, beinahe ohne Abzeichen; das $\delta$ entweder gleich dem $q$ oder häufiger mit dunkeln Partien auf dem Rücken des Thorax und Abdomens von oliv-bräunlicher Farbe (Fig. 6), an den Seiten kräftig gefleckt; Vorderrand des Pronotums und Oberrand der Elytren in beiden Geschlechtern hell, die Schräglinien auf dem Hinterrand der Abdomensegmente beim $q$ kaum angedeutet, beim đotwas kräftiger. Scheitel sehr steil abfallend, breiter als bei den 2 vorhergehenden Formen, concav, mit sehr scharf erhabener Umrandung, die nach hinten offen, nach der Scheitelspitze zu unter einem scharfen Winkel abbiegt, über den Augen parallel verläuft, ein zart angedeuteter Mittelkiel reicht bis zum Hinterkopf. Fühler von gelblicher Farbe, in der 2. Hälfte etwas angeraucht, 17 gliedrig. Pronotum sandig rauh, mit ziemlich gewölbtem Mittelkiel, der von der Hauptquerfurche durchschnitten wird, Meso- und Metanotum sammt ihren Seiten, vom Abdomen nur die 2-3 ersten Tergite, ebenfalls sehr rauh. Die Elytren reichen in beiden Geschlechtern nahezu oder ganz an den Hinterrand des Metanotums. Hinterschenkel flach, mässig breit, mit hoher scharfer undeutlich gesägter Oberkante, deren Aussenseite weiss granulirt ist wie auch die der Unterkante, Innenfläche zart karminroth und weiss gesprenkelt, Aussenfläche $q$ einfärbig, ठ öfters mit braungrünen Flecken, leicht gefiedert, Hintertibien $q$ innen hell karminroth, o gelb. Supraanalplatte des Weibchens in der Mitte mit 2 hinter einander liegenden annähernd herzförmige Vertiefungen, deren Seitenränder kielartig aufgeworfen, weiter aus einander stehen, als bei $P$. marmoratus auf dem spitzen Endtheil aber divergirend sich verlieren. Punktirung an Kopf, Körper und Gliedmaassen zart. 


\begin{tabular}{|c|c|c|c|c|c|}
\hline \multirow{2}{*}{ Länge } & \multirow[b]{2}{*}{ des } & \multicolumn{3}{|c|}{$\delta$} & ? \\
\hline & & Körpers & $48-51$ & $\mathrm{~mm}$ & $62-69 \mathrm{~mm}$ \\
\hline 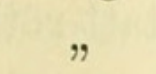 & & Pronotums & $11-12$ & $"$ & $13-16 \quad$ \\
\hline & der & Elytren & $10-11$ & $"$ & $9,5-12$ \\
\hline & $n$ & Hinterschen & $19-21$ & 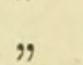 & $19,5-22,5$, \\
\hline
\end{tabular}

Fundort: Djelfa 30.6. 97 in den bergigen nördlichen und nordwestlichen Theilen in grösserer Anzahl auf steinig-sandigem Grunde, einige Male an Euphorbien sitzend.

Diese im weiblichen Geschlecht ganz auffallend dem Eunapius granosus StaL in Grösse, Farbe und Structur der Haut ähnliche Species bildet wohl das südlichste Glied der Pamphagus marmoratus elephas-Gruppe, unterscheidet sich regelmässig davon durch die Form des Scheitels und der Oberfläche der weiblichen Analplatte und die Färbung der Innenfläche der Hinterschenkel; in den Grössenverhältnissen und in der Färbung nähert sie sich der var. tunetanus, ist aber gedrungen und rauher.

Sehr bemerkenswerth ist die Beständigkeit, mit welcher die $ठ ð$ der zwei letztgenannten Formen trotz der Verschiedenheit der ${ }_{+\rightarrow}$ die Zeichnung und Färbung des $P$. marmoratus Männchens wiederholen. Dies bildet einen weitern Hinweis darauf, dass eben $P$. marmoratus und nicht elephas als Stammform anzusehen ist.

Auffallend viele Exemplare waren von Ameisen angegriffen, Mundwerkzeuge und Gliedmaassen verletzt oder abgebissen oder der ganze Körper ausgehöhlt.

\section{Eunapius sitifensis (BRIS.).}

Eunapius brunneri StÅl, Brunner, Prodr., p. 109; Krauss u. Vosseler, p. 541.

Eunapius sitifensis (BRIs.) Finot, p. 519.

Fundorte: Bou Saâda 5.|7. 97; Djelfa 30.6.; von hier klein, die q grün gefärbt, $56-58 \mathrm{~mm}$, bei Bou Saâda aber sehr gross $(63 \mathrm{~mm})$; scheint in Tunesien zu fehlen. In Laghouat 23.6. wurde nur ein von Ameisen skeletirtes + gefunden.

\section{Eunapius quadridentatus (BRIS.).}

Fundort: nur bei Djelfa gemeinsam mit der vorigen Species gefunden 30./6. 97; von Bonnet und Finot auch in Tunesien beobachtet. Das Männchen bis jetzt sehr selten; bei Djelfa, wie früher bei Mecheria, nur ein Mal gefunden. Die wenigen Stïcke sind sehr 
klein (ð 30, q $38-40 \mathrm{~mm}$ ) gegen die von Mecheria (ð $32, q 45-57 \mathrm{~mm}$ ), aber vollkommen gleich gezeichnet, nur ist Zeichnung und Färbung etwas lichter, flauer, die Hintertibien innen blauschwarz statt röthlich violett.

\section{Platyphyma giomae (Rossi).}

Nur bei Dra el Mizane 19./7. 97 und Aumale 11./7. angetroffen, bewohnt wahrscheinlich nur einen schmalen Küstenstrich, ist häufiger gegen Westen (Oran) als gegen Osten.

\section{Dericomys millieri Finot.}

Seltener an der Küste, in der Wüste stellenweise sehr gemein. Fundorte: Laghouat 22.6. 97; Hammam el Lif 28./6. 01, Gafsa 21.6.

Eine sehr beständige Art; meine Ausbeute enthält nur nebensächliche Farbabänderungen: ein ơ aus Gafsa ist strohgelb, eine Larve eben daher rothbraun, eine andere von Hammam el Lif spangrün, entsprechend den Salsolaceen der Umgebung gefärbt. Erzeugt vielleicht eine zweite Generation im Jahre, worauf zahlreiche junge Larven neben entwickelten Thieren sowie die Angabe Frnot's, dass sie erst im Herbst erwachsen sei, hinweisen. Ihre Vorliebe für salzhaltigen Boden war wiederholt $\mathrm{zu}$ beobachten. ${ }^{1}$ )

\section{Acridium aegyptium (L.).}

Fundorte: Bou Saâda 7./7. 97, Laghouat 24./6. Stets nur vereinzelt beobachtet, wegen seiner grossen Vorsicht schwer zu erjagen.

\section{Schistocerca peregrina (OL.).}

Fundorte: Bou Saâda 5./7. 97, Djelfa 3./7. im Nordwesten der Stadt häufig, offenbar im Begriff, sich zu Schwärmen zu vereinigen, ausschliesslich die rosarothe durchschnittlich schlankere Form; Laghouat 29./.6 zahlreiche todte Exemplare in der Umgebung, alle, auch die wenigen lebenden, intensiv gelb; Gafsa 22.6. 01 selten, Graïba 19./6. nur Larven, diese bald grün mit weissen Punkten, bald vollkommen gelb. Trotz ihrer weiten Verbreitung aus Sicilien noch nicht erwähnt.

1) Bolivar, Catal. sinopt., p. 83, führt neuerdings die Art auch aus Spanien an, d. h. eine von ihm als var. carthago-novae beschriebene kurzflüglige Varietät, in: Ann. Soc. Esp. Hist. nat., Actas. Junio 1897. 
68. Thisoicetrus littoralis (RАмв.).

So weit verbreitet die Art ist, so selten erhielt ich sie. Aehnlich wie Caloptenus erstreckt sie sich von der Küste bis zur Wüste. Das einzige Exemplar stammt von Laghouat 22.6. 97.

\section{Caloptenus italicus (L.).}

Im Hinblick auf die grosse Veränderlichkeit glaubt Finot die Aufstellung von Varietäten für unwichtig halten zu sollen, eine Anschauung, der ich in diesem Falle deshalb nicht beizupflichten vermag, weil mir mein algerisches und tunesisches Material zeigt, wie ganz allmählich nach ganz bestimmten Richtungen, offenbar unter dem Einfluss der Umgebung, einzelne Eigenschaften verschwinden, andere dafür erscheinen. Mit Leichtigkeit sind die extremsten einerseits der Küste andrerseits den südlichsten oder östlichsten Landestheilen entstammenden Formen zu unterscheiden. Die erstern sind durchweg sehr gedrungen, von normaler Grösse, ihre Flugorgane überragen das Abdomen nicht oder kaum, sind aber oft kürzer als dieses; ab und zu werden die Flecken auf den Elytren klein und fallen weniger durch dunkle Farbe auf, dafür aber erscheint eine der Hauptsache nach zwischen der Vena ulnaris posterior und Vena dividens verlaufende helle Längsbinde (var. marginellus SERv.). Die 2-3 auf dem Oberrand der Hinterschenkel sichtbaren dunklen Binden setzen sich auf die blasse Innenfläche fort, die häufig von der Insertion aus ein wenig karminrosa wie die Flügel überlaufen ist; dieselbe Farbe trägt die Innen- und Oberseite der Tibien, nur bei einem beinahe ganz schwarzen $q$ von Saïda kommt das Rosa nicht recht zur Geltung. Roth der Flügel kräftig, bis an den Hinterrand reichend.

Hierher gehören die Stücke von Bouira 16./7. 97, Aumale 10./7. und die früher im Norden Orans erbeuteten; sie lebten alle in vegetationsreichem Gebiet oder im Culturland. Als gute Varietät betrachte ich

\section{9a. Caloptenus italicus var. deserticola $n$.}

Flugorgane stets länger als das Abdomen. Elytren mit kleinern Flecken, selten mit der vorhin erwähnten Längsbinde, am Ende abgerundet, nicht zugespitzt, das Roth der Flügel schwächer, den Hinterrand kaum oder gar nicht erreichend. Innenfläche der Hinter- 
schenkel in den ersten zwei Dritteln tief glänzend schwarz, gegen das Ende leuchtend orangeroth; Hintertibien innen und oben ebenso gefärbt. Weiterhin sind die Antennen meist ganz hell, der Hinterrand des Pronotums mehr winklig als bei der Stammform. In der Grösse schwankt die Varietät ziemlich; alle Exemplare von Laghouat sind auffallend klein und zierlich, die von der ost-tunesischen Küste und Gafsa normal, aber von schlankem Habitus.

Länge

des Körpers

, Pronotum

der Elytren $\delta$

Tunis Laghouat

$13-15 \mathrm{~mm} \quad 16-20 \mathrm{~mm}$

$3,5-4,5$

$16-23$

$11-13$

$$
3-4 \quad
$$$$
13,5-18
$$$$
\text { " }
$$

$10-11,5$,
Tunis Laghouat $32-35 \mathrm{~mm} \quad 29 \mathrm{~mm}$ $6,5-7,5,6$, $28-33$ " 24 ” $10-12 " 18$ "

Schon Finот hat die Aufstellung einer besondern Wüstenvarietät angedeutet, aber nicht durchgeführt. In manchen südlichen Gegenden verschwindet das Roth der Flügel vollends ganz (var. siculus BuRM.). Mehrere Exemplare wurden nach Südsturm am Licht gefangen.

Fundorte: Laghouat 22.6. 97; Hammam el Lif 28.6. 01; Gafsa 22.6; Gabès 15.6.

Besonders sei noch darauf hingewiesen, dass sich auch bei dieser Varietät nach Norden die Flügel verkürzen, z. B. bei Hammam el Lif unweit von Tunis nur $28 \mathrm{~mm}$ Länge haben, aber immer noch das Abdomen überragen.

\section{Locustodea.}

\section{Odontura algerica $\mathrm{BR}$.}

Auch diese Species wurde in Oran viel häufiger als auf den letzten Reisen angetroffen.

Fundorte: Medeah 15.6. 97; Bir bou Rekbah 26./6. 01 nur Larven auf Oleandern.

\section{Rhacocleis annulata FIEB.}

Zahlreich auf den Salsolaceen zwischen Bahnlinie und Meer südlich von Hammam el Lif 28.6. 01. Nachträglich auch unter den bei Saïda, dem ersten algerischen Fundort, gesammelten Locustodeen entdeckt. Nur wenige Individuen waren geschlechtsreif. 


\section{Decticus albifrons (FABR.).}

Bei Aumale 10.6. 97 häufig; aber sehr scheu, besonders die Weibchen; fast nur auf die Küstenzone beschränkt.

\section{Ctenodecticus vasarensis FIN.}

Fehlt bis jetzt noch aus Tunis; von mir bei Dra el Mizane 18.7. auf den Bergen angetroffen.

\section{Platycleis tesselata (Сharp.).}

Gemeinsam mit der vorhergehenden Species nördlich von Dra el Mizane 18./7. gefunden; nur auf dem Küstenstrich, nicht im Innern lebend.

\section{Platycleis laticauda BR.}

Dra el Mizane 19.7. 97, Aumale 10.7.

\section{Ephippigera latipennis FisCH.}

In Tunesien noch nicht gefunden, von mir nur einmal bei Dra el Mizane 19./7. 97 angetroffen, das of durch die enorme Ausbildung. des äussern Geschlechtsapparats ausgezeichnet.

\section{Ephippigera compressicollis FISCH.}

Südlich von Aumale in ungefähr 1200 m ü. M. 13./7. 97 gefunden, aus Tunesien noch nicht bekannt.

\section{8. (?) Ephippigera confusa Fiv.}

Trotz einiger Abweichungen von der Originalbeschreibung Finot's stelle ich eine Anzahl von Exemplaren hierher, da sie noch am besten mit dieser Species übereinstimmen. In beiden Geschlechtern sind die Antennen fein behaart, das Ende einzelner in bestimmten Abständen auftretender Ringe ist dunkel. Vorderschenkel kaum oder nicht länger als die Mittelschenkel; Elytren erreichen die Mitte des ersten Abdominalsegments, das Marginalfeld nur beim $q$ abgeplattet, beim o aber stark eingezogen. Legestachel hat nur $1 \frac{1}{1} / 2$ mal die Länge des Pronotums. 


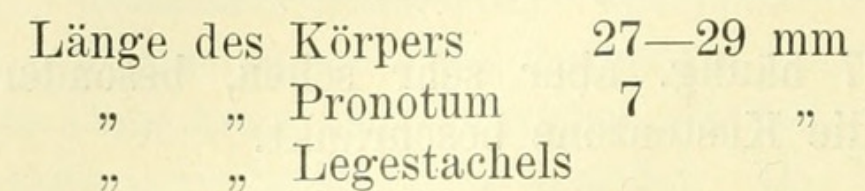

$$
\begin{gathered}
28-32 \mathrm{~mm} \\
7-7,5 \quad " \\
10-12 \quad \%
\end{gathered}
$$

Die Farbe ist grün oder gelbbraun, passt ausgezeichnet zu den Disteln, auf denen die Thiere sassen.

Die angeführten Verschiedenheiten können wohl mit localer Anpassung zusammenhängen, zur Aufstellung einer besondern Varietät oder Art reichen sie nicht aus. Zu den von Finот aufgezählten 3 Fundorten kommen als weitere: Dra el Mizane 19./7. 97, Bouira 16./7.

\section{Ephippigera nigromarginata Luc.}

Zwischen den Segmenten des Abdomens ist die Haut schön rothviolett gefärbt. Scheint in Tunesien häufiger als in Algerien zu sein, kommt auch in Sicilien noch vor. Fundort: Hammam el Lif 28./6. 01 auf Zizyphus.

\section{Ephippigera nerii n. sp.}

(Taf. 18, Fig. 7-8.)

Verwandt mit E. algerica BR. und mit E. antennata BR.

Antennen haben aber nicht 3 fache Körperlänge, sondern nur doppelte (Alkoholexemplare), nur die ersten Ringe auf der Oberseite hell und dunkel geringelt, die spätern oben fast schwarz, unten gelbgrün, von der Mitte an alle dunkel. Kopfgipfel mit kleinen oben gefurchten Höckerchen. Pronotom (Fig. 7 a,b) ganz besonders kantig, rauh, so lang wie breit, Hauptquerfurche tief, gerade, ziemlich genau in der Mitte, vordere Querfurche etwa im ersten Viertel, gebogen; Seitenlappen scharfkantig angesetzt, glänzend glatt, mit wenig Erhabenheiten, in der Mitte etwas eingedrückt, Unterrand ein wenig wellig verlaufend, Mittelkante auf der Metazone ziemlich deutlich. Elytren aufgetrieben, beim $\delta$ mehr als beim ${ }_{+}$, gelbbraun mit schwarzem Discus und Felderchen, besonders am flachen Randfeld. Vordertibien mit Ausnahme eines kleinen Enddornes auf der Oberseite glatt. Hinterschenkel $2^{1 / 2}$ mal so lang wie das Pronotum, auf der untern Innenwand 3-4 ganz kleine Dörnchen, der Aussenwand glatt. Der Fortsatz der Supraanalplatte kurz, dreieckig, breiter als lang, in der Mitte eingedrückt, das Ende fast spitzig. Cerci 
des $\delta$ kurz, conisch, leicht einwärts gebogen, mit einem kräftigen etwa im letzten Drittel sitzenden schwarzen Innenzahn (Fig. 8b), die des $q$ einfach conisch, bei beiden fein behaart. Die Subgenitalplatte des ơ überragt die Cerci nicht, ist am Ende tief dreieckig. ausgeschnitten (Taf. 18, Fig. 8a), ihre Styli sind dünn, schlank, die des + breiter als lang, an den Seiten sich verschmälernd, Legestachel gut doppelt so lang wie das Pronotum, fast gerade am Ende fein gekörnelt.

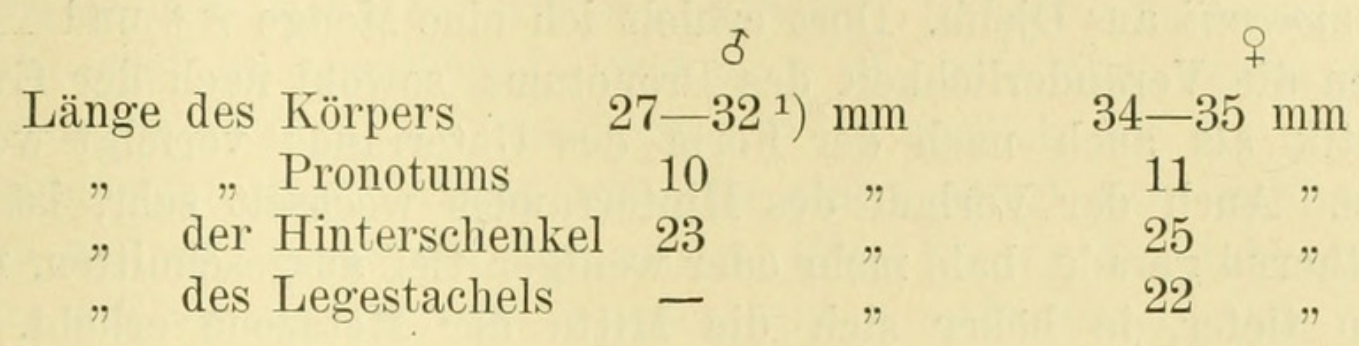

Von E. brevicollis FiscH. und antennata BRUN. unterscheidet sich die neue Art dadurch, dass deren Supraanalplatte am Ende nicht gerundet ist. Der Zahn der Cerci im letzten Drittel statt am Ende sitzt; bei brevicollis sind ferner beide Unterkanten der Hinterschenkel mit zahlreichen Dörnchen besetzt, bei antennata aber ist das Pronotum länger als breit.

Die in manchen Punkten herrschende Uebereinstimmung mit $E$. algerica $\mathrm{BR}$, deren o noch nicht bekannt ist, verliert an Bedeutung dadurch, dass dort die Hauptquerfurche hinter der Mitte des Pronotums liegt, die Vordertibien 3 Dörnchen auf der Oberseite tragen, beide Unterkanten des Hinterschenkels bedornt sind, der Legestachel $2^{1 / 2}$ mal so lang wie das Pronotum ist. Von E. Tucasi Br., die etwa noch zu vergleichen wäre, ist die Art endlich schon durch die Form der Elytren und den geringern Umfang des Pronotums scharf getrennt.

Fundort: Bir bou Rekbah 26.6. 01 stets auf Oleandern. Die Fühler gerade nach vorne gestreckt, sitzen $\delta, q$ und Larven gerne in den Enden der Zweige, sind tadellos angepasst, nehmen keinerlei Vertheidigungsstellung ein, zirpen beim Fange ein wenig.

\section{Ephippigera innocentii Bonn. et Fin.}

Ephippigera lobata SAuss., Anal. Entomol., in: Rev. Suisse Zool., V. 5, p. 236.

1) Aus Alkohol; die andern Maasse nach getrockneten Exemplaren. 
Auf Grund einer lappenförmigen Erweiterung am Unterrand der Seitenlappen des Pronotums trennt de Saussure die Form aus Oran von der typischen $E$. innocentii als eigene Art ab, innerhalb welcher er noch 2 Varietäten aufführt. Seine Beobachtung ist im Ganzen richtig; auch die meisten meiner Exemplare aus Mecheria, Aïn Sefra und Tiout, Larven wie Imagines, sind durch die charakteristische lobata-Form des Unterrands ausgezeichnet. Darunter aber befinden sich wieder solche, wo dies kaum deutlicher ist als bei einigen echten E. innocentii aus Djelfa. Dort erhielt ich eine Menge of und +9 , an denen die Veränderlichkeit des Pronotums, sowohl nach der Grösse, Plastik als auch nach der Form des Unterrands verfolgt werden kann. Auch der Verlauf des Hinterrandes wechselt sehr, ist bald annähernd gerade, bald mehr oder weniger tief ausgeschnitten, meist desto tiefer, je höher sich die Mitte der Metazone erhebt. Die extremste Ausbildung des Läppchens fehlt in Djelfa, ist also wohl auf den Süden Orans beschränkt, und so kann immerhin eine besondere Varietät aus der von dort stammenden Localform gemacht werden. Im Uebrigen sind Hinweise auf die Unbeständigkeit einzelner Charaktere schon bei Fıмот (p. 548-49) aufgeführt. In allen übrigen Merkmalen stimmt die var. lobata mit der Stammform überein, besonders auch im Bau des äussern Genitalapparats. Die Zeichnung der Abdominaltergite, welche de Saussure zu Aufstellung der var. picturae veranlasste, tritt auch bei der Stammform von Djelfa in allen Abstufungen auf, fehlt selten ganz, bei der var. lobata von Süd-Oran ist der Rücken der Larven bestimmter gezeichnet als der der erwachsenen Thiere.

Fundorte: Djelfa 3./7. 97, Bou Saâda 7./7. Im Westen von Djelfa fand ich die Art sehr häufig bis über eine Postwagenstunde von der Stadt sich verbreitend. Im Verein mit Platystolus wanderten gegen Abend, ruckweise bald da bald dorthin sich wendend, die Thiere auf der Strasse, sammelten sich oft gruppenweise auf den Excrementen der Pferde, Rinder oder Kameele, die sie lebhaft mit dem Lagestachel durchstocherten, offenbar in der Absicht ihre Eier dort abzulegen. Ein einziger Nachmittag lieferte eine Ausbeute von 60 Stück, welche aus Mangel an andern Transportmitteln mit einer grössern Anzahl von Platystolus in einem Sack nach Hause transportirt, von diesen aber unterwegs nahezu total aufgefressen wurden. Trotz reichlichen Futters verzehrte ein $q$ ein erwachsenes $\delta$ in der Gefangenschaft binnen kürzester Frist bis auf den letzten 
Rest. ${ }^{1}$ ) Am liebsten scheint sich die Art auf den niedern sparrigen Büschen einer graugrünen Centaurea, mit der ihre Farbe correspondirt, aufzuhalten. Ist die einzige Ephippigera, welche noch in der Wüste vorkommt.

\section{Platystolus pachygaster (Luc.).}

Bei Djelfa recht häufig in Gemeinschaft mit der vorigen Art; im Allgemeinen mehr der Küste angehörig, in der Umgebung von Aumale noch in annähernd $1200 \mathrm{~m}$ ü. M. gefunden, reicht über Tunesien bis Sicilien und Sardinien. Wird ähnlich wie die meisten Ephippigeriden gegen Abend lebhafter und wandert gern in Stoppelfeldern und an Strassenrändern umher. Zwei of wurden dabei überrascht, als sie im Begriffe standen ein $\delta$ aufzuzehren, ein noch lebendes + war, offenbar ebenfalls von Artgenossen schwer verletzt, schliesslich von Pimelien als Leckerbissen angegriffen worden. Aus ihrem Verhalten in Gefangenschaft geht ebenfalls hervor, dass Platystolus wohl die vollendetste Räuber- und Kannibalennatur unter allen paläarktischen Locustodeen besitzt; man weiss nicht, ob man seine Mordlust oder Fressgier mehr bewundern soll. Auf dem früher erwähnten Transport waren nur ca. 6 Weibchen von Platystolus ganz unverletzt übrig geblieben, welche in kürzester Zeit ein fürchterliches Massacre angerichtet, sich selbst aber bis zum Bersten angefüllt hatten. Die reifen Eier aus den Eileitern sind $6 \mathrm{~mm}$ lang $2 \mathrm{~mm}$ breit, spindeliörmig leicht zusammengedrückt, von hellbrauner Farbe. Ueber sein Vermögen, Blut zur Vertheidigung aus dem Pronotum abzugeben, sowie über den Bau der Spermatophoren wird in dem allgemein biologischen Abschnitt Weiteres ausgeführt.

Fundorte: Aumale 13.7. 97. Djelfa 29.6.; ausserdem wurde er noch an verschiedenen Stellen, wie namentlich bei Berrouaghia, zwischen Bou Saâda und Aumale, vom Postwagen aus beobachtet.

Die Grösse der o+ schwankt zwischen 29 und $45 \mathrm{~mm}$ (ohne Legestachel), die der ठठठ von 34 bis $44 \mathrm{~mm}$.

1) Brunner, Prodr., p. 368, hält die Ephippigeriden für ausschliessliche Pflanzenfresser. 


\section{Eugaster guyoni SERv.}

$\mathrm{Zu}$ den von Krauss benannten Varietäten aus Oran (p. $551 \mathrm{f}$.) fanden sich an zwei Orten Uebergänge. Bei Bou Saâda lebt die var. Tucasi, aber mit ganz dunkelrothen, schon beinahe schwarzen Pronotumstacheln und -hinterrand, bei Djelfa entweder die echte var. lucasi oder eine Zwischenform zwischen dieser und der typischen Art, dadurch ausgezeichnet, dass auf dem Hinterrand der Abdominalringe noch die rundlichen rothen Flecken auftreten, meist aber den letzten 4-5 mehr oder weniger vollständig fehlen, auf den vordern zudem viel kleiner und weniger grell roth, mehr gelblich gefärbt sind. Die Stacheln an den Seiten der erweiterten Metazone einiger in Gefangenschaft gross gezogener Männchen blieben theilweise stumpf oder waren kaum angedeutet.

Fundorte: Bou Saâda 7.7. 97, Djelfa 29.6. Tritt an beiden Orten wie gewöhnlich vereinzelt auf. Verschiedene Larven und Imagines wurden zum Zweck biologischer Beobachtungen lebend erhalten und hielten sich bis Anfang November. Die Eiablage wurde durch frühzeitigen Tod an Gregarinose verhindert, dagegen konnten einige Untersuchungen über Begattung, Spermatophoren, Häutung und Blutspritzen ausgeführt werden (vgl. II. Theil).

Die neuen Funde beweisen abermals, dass die rothgefleckte Form den Typus darstellt, denn auch deren Larven sind stets reich mit diesen Auszeichnungen versehen. Durch die erwachsenen Individuen wird im Verein mit den früher unterschiedenen Varietäten eine lückenlose Entwicklungsreihe der Zeichnung und Färbung hergestellt, aus der hervorgeht, dass das Roth von hinten nach vorn allmählich verschwindet, am längsten sich an den Stacheln des Pronotums erhält.

\section{Gryllodea.}

\section{Platyblemmus umbraculatus (L.).}

Fundorte: Medeah 15.6. 97, Frais Vallon bei Algier 9./7.

Das von Finot zur Unterscheidung der Arten benutzte Verhältniss der Flügel- zur Abdomenlänge ist bei getrockneten Exemplaren sehr unzuverlässig. 


\section{5. (?) Gryllees hygrophilus Krauss.}

Gryllus hygrophilus Krss., in: Verh. zool.-bot. Ges. Wien, V. 52, 1902.

Erinnert in einigen Punkten an Gr. consobrinus SAuss. Der Hinterrand des Pronotums ist nicht breit umgeschlagen. Pronotum mit wenig dunklen Fleckchen, seine Seitenlappen hell mit einem centralen schwarzbraunen Flecken und einigen Punkten. Die Elytren wie die Grundfarbe des ganzen Thieres hellbräunlich, mit wenig Abzeichen, vor allem die Adern nicht dunkler. Elytren beim o die 3-4 letzten Abdominalsegmente frei lassend, beim $q$ noch kürzer. Flügel viel kürzer als die Elytren, blass. Die Beine gelblich bis hellbraun, die zwei vordern Paare einfarbig, das hintere mit wenig braunen Fleckchen am Ende des Femur. Legestachel $8 \mathrm{~mm}$, länger als Hinterschenkel, Cerci des o (getrocknet) $6,5 \mathrm{~mm}$, die des đo kürzer.

Fundort: Gabès 15.6. 01 in grosser Anzahl zwischen Binsen auf dem salzhaltigen Boden in der Nähe des Oued sich tummelnd angetroffen, aber nur wenige gefangen, da sie sich sehr geschickt in den Pflanzen zu verstecken wissen.

\section{Gryllus burdigalensis LATR.}

Stimmt ähnlich der Hausgrille in den Wohnungen von Gafsa, vor allem im Bahnhofgebäude, ein sehr lautes Concert an, ist aber trotz ihrer Menge schwer zu erhaschen.

Fundort: Gafsa 21.|6. 01.

\section{Gryllomorpha uclensis Pans.}

Bei Gafsa 21.6. 97 unter Steinen eine Larve im letzten Entwicklungsstadium gefunden; kommt auch in Spanien und Algerien vor. 
88. Tridactylus variegatus LATR.

Lebt in grosser Anzahl im feuchten Sande des Flussbettes in der Oase von Bou Saâda 8./7. 97; durch die Erschütterungen des Bodens beim Auftreten kommt sie aus ihren kleinen Löchern hervor, schnellt sich, trotz ihrer Kleinheit, bis $50 \mathrm{~cm}$ weit, vermag auch von der Oberfläche des Wassers abzuspringen. 


\section{$2 \mathrm{BHL}$ Biodiversity Heritage Library}

Vosseler, Julius. 1902. "Beiträge zur Faunistik und Biologie der Orthopteren Algeriens und Tunesiens." Zoologische Jahrbücher 16, 337-404. https://doi.org/10.5962/bhl.part.17152.

View This Item Online: https://www.biodiversitylibrary.org/item/38159

DOI: https://doi.org/10.5962/bhl.part.17152

Permalink: https://www.biodiversitylibrary.org/partpdf/17152

\section{Holding Institution}

MBLWHOI Library

\section{Sponsored by}

MBLWHOI Library

\section{Copyright \& Reuse}

Copyright Status: NOT_IN_COPYRIGHT

This document was created from content at the Biodiversity Heritage Library, the world's largest open access digital library for biodiversity literature and archives. Visit BHL at https://www.biodiversitylibrary.org. 